University of Florida Levin College of Law

UF Law Scholarship Repository

UF Law Faculty Publications

Faculty Scholarship

Summer 2008

\title{
Value in the Eye of the Beholder: The Valuation of Intangibles for Transfer Pricing Purposes
}

Yariv Brauner

University of Florida Levin College of Law, brauner@law.ufl.edu

Follow this and additional works at: https://scholarship.law.ufl.edu/facultypub

Part of the Taxation-Transnational Commons, and the Tax Law Commons

\section{Recommended Citation}

Yariv Brauner, Value in the Eye of the Beholder: The Valuation of Intangibles for Transfer Pricing Purposes, 28 Va. Tax Rev. 79 (2008), available at http://scholarship.law.ufl.edu/facultypub/18

This Article is brought to you for free and open access by the Faculty Scholarship at UF Law Scholarship Repository. It has been accepted for inclusion in UF Law Faculty Publications by an authorized administrator of UF Law Scholarship Repository. For more information, please contact kaleita@law.ufl.edu. 


\section{VALUE IN THE EYE OF THE BEHOLDER: THE VALUATION OF INTANGIBLES FOR TRANSFER PRICING PURPOSES}

Yariv Brauner

\section{TABLE OF CONTENTS}

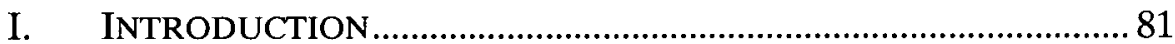

II. INTANGIBLES ARE DIFFERENT AND IMPORTANT …………….....8 85

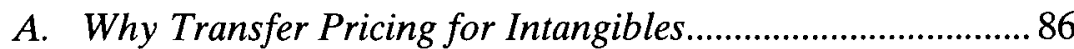

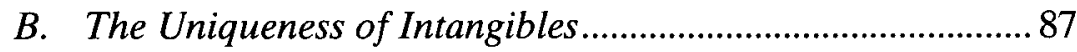

1. Why Are Intangibles Difficult to Valuate? ...................... 87

2. Primary Value Drivers and Value Detractors.................. 89

C. Intangibles and MNEs .......................................................... 92

III. TRANSFER PRICES AND THE VALUATION OF INTANGIBLES.... 95

A. The Arm's Length Standard ................................................... 96

1. Background ………………………................................... 96

2. Universality ........................................................................ 99

3. Commensurate with Income ........................................... 100

4. Tax Policy Implications of the Arm's Length

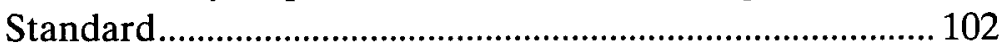

B. The Market Approach ......................................................... 104

1. The Market Approach to Valuation in General.......... 104

2. The Market Approach as Applied to Valuation of

Intangibles for Transfer Pricing Purposes .......................... 107

C. The Cost Approach to Valuation........................................... 109

1. The Cost Approach in General....................................... 109

- Associate Professor of Law, University of Florida, Levin College of Law. I thank Lawrence Lokken, Paul McDaniel, Lauren O'Dower for their helpful comments and assistance. All mistakes and inaccuracies are mine. 
2. Application of the Cost Approach to Valuation of Intangibles

3. The Cost Approach to Valuation in Practice ................ 111

4. Assessment of the Cost Approach ................................. 113

D. The Income Approach to Valuation....................................114

1. The Income Approach in General................................. 114

2. The Operation of the Income Approach ....................... 116

a. The Technique of Income-Based Valuation ..... 118

3. Assessment of the Income Approach to Valuation of Intangibles.

E. Other Approaches and Conclusions 120

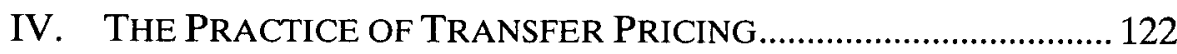

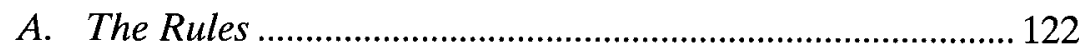

1. General Rules and the Arm's Length Principle............ 123

2. The Analysis................................................................ 124

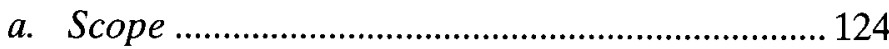

b. Ownership ....................................................... 125

c. Valuation and Attribution of Profits .................. 127

3. The Intangibles Methods............................................... 128

a. The Comparable Uncontrolled Transaction ("CUT") Method ...................................................... 128

b. Comparable Profits Method............................... 130

c. Profit Split Method ............................................ 132

d. The Fourth Method ................................................ 133

e. Conclusion ............................................................. 134

B. In the Courts .............................................................................. 134

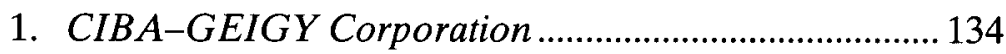

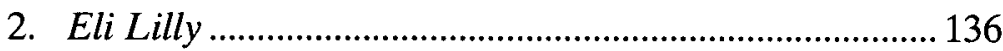

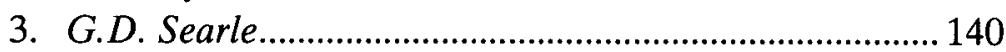

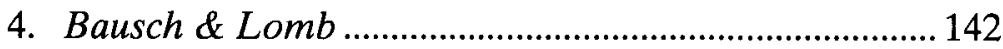

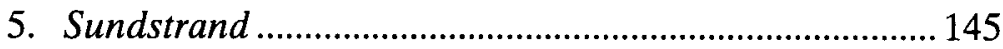

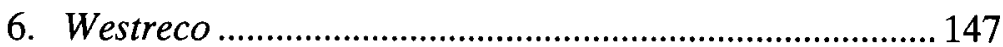

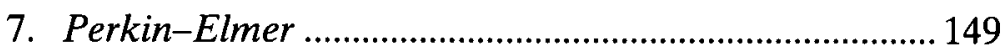

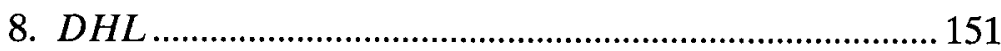

C. Endnotes on the Practice of Transfer Pricing for Intangibles................................................................................ 154

V. CONCLUSION: THE FUTURE OF TRANSFER PRICING ............... 156

A. The Reality of Current Law .......................................................

B. The Challenges Faced by the Arm's Length Principle ...... 157 


\section{The Future of Transfer Pricing Is in a Formula-Based} Regime

\section{INTRODUCTION}

Can one put a price on the priceless ${ }^{1}$ The practical answer must be yes since taxpayers are required according to our transfer pricing rules to price (or assign value to) intangibles they transfer to related parties. ${ }^{2}$ The thriving valuation industry that focuses on intangibles clearly indicates a belief that this is the case. ${ }^{3}$ In fact, many countries, including essentially all of the major economies, adopted transfer pricing legislation similar to that of the United States. ${ }^{4}$ Compliance with these rules relies heavily on accurate valuation of the transferred intangibles. This article evaluates to what extent this practice of valuation is accurate, and whether it can support this widespread confidence. In light of this evaluation, the article assesses the desirability of our current transfer pricing regime.

Transfer prices are prices required to be reported in related-party transactions for tax purposes. ${ }^{5}$ Transacting taxpayers are required to establish their transfer prices whenever they transact with related parties, even if they have no other (e.g., business) reasons for such (internal) pricing. As a rule, transfer prices should be based on the arm's length principle, ${ }^{6}$ in which the transacting related parties are taxed similarly to the manner in which they would have been taxed if they were unrelated parties engaged in similar transactions charging

${ }^{1}$ A price on the priceless, THE ECONOMIST, June 12, 1999, at 61.

2 See I.R.C. \$482; Treas. Reg. \$1.482-4 (2006).

3 The leaders are the big four accounting firms, yet a large number of independent service providers emerged over the last years. See, e.g., http://www.transferpricingconsortium.com/TPChome.html; http://www.valuationresearch.com/content/Services/Transfer_Pricing.htm; http://www.precisionecon.com/?gclid=CJjJu_DR_JECFQpTHgodPyEr3Q;

http://appraisaleconomics.com/transfer.html. These are simply the first five Google search results. Another good indicator is the constant search for transfer pricing experts by executive head hunter services.

${ }^{4}$ See, e.g., Marc M. Levey \& Steven C. Wrappe, Transfer Pricing: Rules, COMPLIANCE AND CONTROVERSY $\mathbb{1} 180$ ( $2 \mathrm{~d}$ ed. 2008).

5 See I.R.C. $\$ 482$.

${ }^{6}$ Even when the actual rules deviate from this principle, the government has insisted on keeping the rhetoric of adherence to the arm's length principle. We shall come back to this particularly in Part IV.A infra. Note that similar valuation exercises may be required for customs purposes. This article does not discuss the interaction between these two regimes for simplification. 
arm's length (market) prices. ${ }^{7}$ The current international transfer pricing regime is based on, and essentially follows, this principle. ${ }^{8}$

Our transfer pricing rules include specific rules for transfers of intangibles that are separate and distinct from the rules that apply to transfers of other types of assets. ${ }^{9}$ This article focuses on these rules, discussing the theory and practice of valuation of intangibles for transfer pricing purposes in order to address the actual incentives created by the current regime. ${ }^{10}$ In particular, the article wishes to expose the true nature of the valuation process, and determine what the process can and cannot help us with. In the case of intangibles, the reality is that the level of valuation inaccuracy is significant, yet the rules do not account for such inaccuracy. Valuation and measurement tools that aim at reducing uncertainties ${ }^{11}$ are utilized as if they are designed to produce a "fact" - a precise dollar amount presented as a "price" - and treated as such for tax purposes as if they were market prices. ${ }^{13}$

In order to soberly evaluate the current regime, one must first understand the general environment in which transfer pricing rules operate. The basis for these rules is in the observation that society requires taxation (revenue) so it can thrive beyond subsistence, yet taxation is economically inefficient and wasteful. ${ }^{14}$ The administration

7 Treas. Reg. \$1.482-1(b) (2006).

${ }^{8}$ See, e.g., Reuven S. Avi-Yonah, The Rise and Fall of Arm's Length: A Study in the Evolution of U.S. International Taxation. (Univ. of Mich. Law \& Econ., Olin Working Paper No. 07-017, 2007), available at http://ssrn.com/abstract=1017524; see also ERnst \& Young, 2007-2008 Global Transfer Pricing Survey: Global Transfer Pricing TRends, Practices And Analyses, available at http://www.ey.com/Global/assets.nsf/International/EY_Tax_TPSurvey_2007/\$file/Tax _TPSurvey_2007.pdf [hereinafter "ERNST \& YOUNG, 2007-2008 GLOBAL TRANSFER PRICING SURVEY"].

${ }^{9}$ See I.R.C. $\$ 482$; Treas. Reg. \$1.482-4 (2006).

${ }^{10}$ This is a global regime, and part of the international tax regime, yet, for most purposes this article focuses on the aspects of the U.S. transfer pricing regime.

11 Douglas W. Hubbard, How to Measure ANYThing: Finding the Value OF "INTANGIBLES" IN BUSINESS 10-27 (2007).

${ }^{12}$ This is not actually so. See, e.g., Ted Hagelin, A New Method to Value Intellectual Property, 30 AIPLA Q.J. 353 (2002).

${ }^{13}$ At the end of the day, every taxpayer reports her income as one or more distinct dollar amounts to which she applies an appropriate tax rate, and the product of this straightforward multiplication is a single dollar amount owed to or due from the government.

${ }^{14}$ See, e.g., RICHARD A. MUSGRAVE \& PEGGY B. MUSGRAVE, PUBLIC FINANCE IN THEORY AND PRACTICE 303 (3rd ed., 1980). 
of taxes adds to the waste, ${ }^{15}$ and the transfer pricing rules serve as a good example of this, since these rules mandate Multinational Enterprises (MNEs) to produce extensive contemporaneous documentation to support their transfer prices. $^{16}$ This mandate requires MNEs to bear significant costs for the employment of specialists in the legal, economic and valuation fields. ${ }^{17}$ The basic idea behind the system is to pass the burden to taxpayers when the administration cannot make sense of or handle the burden of enforcing the rules. In practice it develops into a stamina test that a taxpayer can pass if she produces enough paperwork that looks relevant. The waste that our transfer pricing rules represent is considered necessary, since without such rules, MNEs could essentially escape taxation, and countries could find themselves in fierce and impossible competition for revenue. ${ }^{18}$

An arm's length based transfer pricing regime, such as ours, permits relatively peaceful division of revenues between countries. ${ }^{19}$ Peaceful, however, does not mean efficient or fair division of revenue. On one hand, MNEs are encumbered with compliance costs that other taxpayers do not bear; on the other hand they benefit from the flexibility that these rules allow. Flexibility means lower effective tax rates overall for such MNEs. Consequently, our tax regime creates an incentive to invest abroad and particularly to invest extensively in intangibles to capture as much of the benefits embedded in the transfer pricing rules.

${ }_{15}$ The source of this waste is enforcement and compliance costs. See, e.g., id. at 302-303.

${ }^{16}$ See, e.g., I.R.C. $\$ 6662(\mathrm{e})$; Treas. Reg. $\$ 1.6662-6(\mathrm{~d})(2)(\mathrm{iii})$ (2006); ERNST \& YOUNG, 2005-2006 GLOBAL TRANSFER PRICING SURVEYS: TAX AUTHORITY INTERVIEWS: PERSPECTIVES, INTERPRETATIONS and REGULATORY CHANGES, available at http://www.ey.com/global/assets.nsf/ International/Tax_Global_Transfer_Pricing_Survey_Part_3/\$file/EY_GlobalTPSurvey 3_Sep2006.pdf [hereinafter "ERNST \& YOUNG, 2005-2006 GLOBAL TRANSFER PRICING SURVEYS"].

${ }^{17}$ See, e.g., ERnst \& Young, 2007-2008 Global Transfer Pricing Survey, supra note 8 .

${ }^{18}$ Note that related party transactions, or intra-firm trade, to which transfer pricing rules apply, is very significant, it increases and promises to be even more important, particularly for the United States in the future. See, e.g., Tanweer Akram, Haider Ali Khan \& James Holladay, U.S. Intra-Firm International Trade (2007), available at $\mathrm{http}: / / \mathrm{ssrn} . \mathrm{com} / \mathrm{abstract}=1030388$.

19 There is consensus because those countries that examined alternative frameworks were forced back into the arm's length based consensus. The classic example is that of Mexico. See Reuven S. Avi-Yonah, Commentary, 53 Tax L. Rev. 167,170 (1999). 
International tax competition may negate the benefits of domestic transfer pricing rules or enhance their biases. In reality, the effect of this competition is somewhat restrained by the international transfer pricing regime, which is an important part of our international tax regime that dictate some basic rules for this competition game. ${ }^{20}$ Nonetheless, since the international tax regime is not based on close cooperation between countries, ${ }^{21}$ such restraint is not significant. Despite the inherent multilateral flavor of transfer pricing law, the main function of which is division of revenue between countries, there is little international policy and administration coordination of transfer pricing.

This article demonstrates that part of the blame is on the arm's length standard. This article proposes that a formula based transfer pricing regime is superior to the current regime on several grounds. For example, it is more effective in general, particularly in the context of intangibles, and it is more accommodating of international coordination and cooperation. It better reflects the very basic principles on which our general international tax regime is based on, thus it is more compatible with the rest of our tax system.

The article proceeds as follows: Part II sets the stage for the analysis explaining the unique features of intangibles that makes intangibles difficult to value. Next, the intimate relationship of intangibles and MNEs is elaborated on in light of the unique characteristics of intangibles in order to explain the importance of valuation of intangibles in the context of transfer pricing.

Part III applies traditional and novel theoretical approaches to the art of valuation of intangibles for transfer pricing purposes. It demonstrates the divorce between our actual scope-limited transfer pricing rules and the richness and sophistication of modern valuation theory. This section exposes the inadequacy of the arm's length principle in the current market place.

This theoretical analysis is followed by a review and assessment of the practice of transfer pricing in Part IV. The current U.S. rules and their use in practice are reviewed first. Then, the article reviews the main cases where the courts attempted to apply these rules. This review demonstrates the difficulty of applying the transfer pricing

${ }^{20}$ Id. at 169 (arguing that the network of bilateral tax treaties "constitutes an international tax regime, which has definable principles that underlie it and are common to the treaties").

${ }^{21}$ See, e.g., Yariv Brauner, An International Tax Regime in Crystallization, 56 Tax L. Rev. 259 (2003). 
rules and the frustration of the courts with this difficulty, which has resulted in the court's use of alternative solutions to resolve the disputes in front of them.

The article concludes, in Part $\mathrm{V}$, with a reassessment of the current arm's length based transfer pricing system and a demonstration of how a formulary system based on international coordination is superior to the current system from the perspective of valuation of intangibles. Extension of this conclusion to a systemwide assessment requires further study, yet since the valuation of intangibles is probably the biggest challenge to contemporary transfer pricing at the present, the outcome of this article should represent a significant step towards reform. ${ }^{22}$

\section{INTANGIBLES ARE DIFFERENT AND IMPORTANT}

Taxpayers are uncomfortable with the requirement that they establish transfer prices for their intangibles. In many cases, the valuation of these intangibles does not seem natural to businesspersons, and they do not engage in such valuations for purposes other than the pathology of the law (i.e., taxes, bankruptcy, or other regulatory purposes). ${ }^{23}$ Their lawyers are even more nervous, and develop an attitude toward this practice that is cynical at best. The reason for this negative attitude is the inherent complexity of the issues and analyses involved and the general uneasiness that lawyers have with uncertainty, especially when uncertainty dominates the "facts" (the value of intangibles in our case).

An understanding of intangibles is an essential first step in explaining the reasons for this complexity and uncertainty. First, this section clarifies the necessity of special transfer pricing rules for intangibles, and the centrality of valuation to such rules. The uniqueness of intangibles is explored next. The article emphasizes the features that make intangibles difficult to valuate (and different from tangible property for these purposes). Highlighting the distinctive features of the different types of intangibles demonstrates the difficulty of using a unitary approach to value all intangibles. These

${ }^{22}$ Despite the intimate relationship between the cost sharing rules, see Treas. Reg. \$1.482-7 (2006), and transfer pricing for intangibles, I chose not to include cost sharing in this article, since I observe several additional issues that one must tackle in the context of cost sharing that are irrelevant to this article. Their assessment must wait for future study.

${ }^{23}$ Measurement is another story, yet it is very different from pricing. See Hubbard, supra note 11 . 
differences are explored, and later analyzed, in order to determine whether different valuation approaches may be warranted for different intangibles.

Finally, this section elaborates on the intimate relationship between intangibles and MNEs, to demonstrate both the importance and significance of intangibles to international trade, which in turn, requires their valuation for transfer pricing purposes. This analysis also adds to the specific features that distinguish transactions in intangibles in the context of transfer pricing (being exchanged by MNEs) from transactions in other assets.

\section{A. Why Transfer Pricing for Intangibles}

Transfer pricing rules are a necessary component of any international income tax law since these rules stop MNEs from easily avoiding or significantly reducing taxation by shifting profits to low or no tax jurisdictions. Since intangibles are important to the operation and existence of MNEs, and since MNEs are major players in a majority of the cross-border intangible transactions, transfer pricing rules naturally apply largely to transactions that involve transfers of intangibles in one way or the other.

To put it more concretely, a transfer pricing analysis is required in any licensing agreement between related entities; in almost any international restructuring of groups of companies; in many intragroup agreements that involve knowledge, research and development, management, organizational or production and manufacturing processes; and even in distribution agreements of tangible products where the value of the product depends on embedded intangibles (e.g., proprietary software).

The following subsection further elaborates on the nonunitary nature of intangibles and the difficulty of applying a unitary approach to all such assets. Despite this difficulty, current law attempts to do just that by applying a single standard to all related party transactions in intangibles. ${ }^{24}$ Moreover, our rules reflect an essentially universal consensus and convergence of transfer pricing norms. ${ }^{25}$ This convergence has positive consequences that will be explored later in this article; however, the price of such convergence is the lack of finely

${ }^{24}$ The singular approach is qualified, mainly through elaborate regulations. Nevertheless, despite the diversity of approaches permitted by the regulations there is no recognition of the differences between intangibles and the consequent potential necessity of different approaches to their valuation.

${ }^{25}$ See supra note 19. 
tuned norms that could respond to the unique features of the specific intangible assets transacted. Criticism of this rudimentary approach is a major theme of this article. Not only is it a problematic singular approach applied to all transactions, but the approach that has been adopted is particularly incompatible with transactions involving intangibles. This approach is problematic because the universal transfer pricing norm applies the arm's length standard to all transactions. ${ }^{26}$ This approach to transfer pricing depends on markets and market prices to serve as benchmarks for the establishment of "transfer prices." This "make believe" approach inherently requires the use of proxies and adjustments that depend on valuation techniques, which are required in every step that one threads.

Next, we explore the unique features of intangibles in more detail. Understanding them will allow us to assess the strength of potential valuation practices, and to evaluate the current transfer pricing rules applying to transactions in intangibles.

\section{B. The Uniqueness of Intangibles}

1. Why Are Intangibles Difficult to Valuate?

Intangibles are all the nonphysical, nonmonetary assets of a firm. ${ }^{27}$ This general definition, however, is not very informative for our purposes. We need to explore various specific and unique characteristics of intangibles to better understand the economics of the transactions that involve them. We shall see also that intangibles come in many forms and certain unique characteristics may be important for transactions in some intangibles but not for others.

Legal protection is one key element in this analysis. The legal framework for the protection of inventions as "intellectual property" is a relatively recent phenomenon, ${ }^{28}$ whereas intangibles have been with us forever. The debates over the appropriateness of intellectual property protection and the terminology itself are beyond the scope of this article, yet it is easy to see how the special legal entitlements that intellectual property laws create affect the value of the exchanged media subject to the transfer pricing rules. The international dimension complicates the picture even more because there are

${ }^{26}$ See supra note 8.

27 Gordon V. SMith \& Russell L. PARr, InTEllectual Property: VALUATION, EXPLOITATION, AND INFRINGEMENT DAMAGES 13 (2005).

${ }^{28}$ Intellectual property is a type of intangible that does receive legal protection. The term "intellectual property" had not been used prior to the mid $19^{\text {th }}$ century. 
inevitably at least two jurisdictions involved in any transfer pricing case, and these jurisdictions may have different approaches to intellectual property laws. It is even possible that the countries involved protect the intellectual property rights of different parties or provide different types of protection. The level of legal protection and its duration clearly affect the value of intellectual property and inherently affect the value of other assets whose value depends on the value of intellectual property. We shall see later in this article that our transfer pricing rules basically ignore this, as well as other possibly relevant distinctions.

An important feature of many intangibles is that they have public goods characteristics, since they are easily diffused. ${ }^{29}$ In many cases the same intangibles are also easy (and cheap) to transfer. ${ }^{30}$ In other cases, however, they may be impossible or very costly to transfer (or at least lose significant value upon transfer). ${ }^{31}$ In these cases, one may reach very different valuations based on what one's approach is: for the owner firm, the latter intangibles may be worth a lot and expected to generate significant income, but for others it may have little value. It is naturally very difficult to reflect this nuance in valuation.

Often, intangibles contribute to the firm, and hence gain value, by interacting with other assets or products of the firm (or being embedded in such assets or products). In this case, it is important to understand the ability to separate the intangibles from these other assets for the purpose of valuation. There are several approaches that may lead to different valuations. An attempt to delineate the value of the intangibles from the embedded tangible property may be easy and reasonable in some, but not all, cases. The sale by a PC manufacturer of a desktop PC with OEM software embedded, say, a word processor, may be delineated quite simply if the software is also sold separately on the market. On the other hand, for example, a complex medical device that includes a piece of highly customized software that may be close to useless with any other machinery presents a much more difficult case of valuation. It might be difficult and quite arbitrary to try and put a separate price tag on the hardware, software, optic device and the various expertise sets involved.

A related feature of intangibles is that they often interact with

${ }^{29}$ Baruch LeV, IntanglBles: Management, Measurement And RePorting 22 (2001).

${ }^{30}$ Take, for example, the secret ingredients of Coca-Cola. Once publicly known, the successful taste of the beverage could be easily and inexpensively replicated, hurting the value of the formula to Coca-Cola.

${ }^{31}$ Think about a management process or "chemistry" of a workforce. 
tangible and financial assets to create value. ${ }^{32}$ Therefore, even if the intangible is not embedded into a tangible product, the intangible may still create value that could not be captured by separately valuing the participating assets, assuming such separation were possible.

The feasibility of separating the various assets valuated and writing a contract that describes accurately the intangible (if one wishes to sell or purchase it) are important as well. Cohesiveness of the workforce or management, for instance, may be very valuable to a firm, yet it is difficult to see how the firm can sell it. In addition to the inability to write this into the contract, it may not be practically separated from the owner firm or "transferable" (even if the entire workforce remained in place, say, after an acquisition by a rival firm). Some intangibles are transferable, but only at a high cost or unpredictable chance of success. Such intangibles are, again, tricky to valuate.

\section{Primary Value Drivers and Value Detractors}

Baruch Lev, a leading scholar in the field of the economics of and accounting for intangibles, defines intangibles as "nonphysical sources of value (claims to future benefits) generated by innovation (discovery), unique organizational designs, or human resource practices." ${ }^{33}$ The definition highlights three quite distinct groups of intangibles categorized by the source of their value. Lev further asserts that the two major drivers of benefits from intangibles are nonrivalry and network effects, while partial excludability, inherent risk, and nontradability are their primary value detractors. ${ }^{34}$ Next, I elaborate on how these factors affect the value of intangibles.

Nonrivalry or scalability is the first attribute that one thinks about when noting the uniqueness of intangibles, since many benefits from intangibles have low or no opportunity costs. ${ }^{35}$ This is related to the ease-of-transfer point mentioned above. For example, if corporation $\mathrm{X}$ developed a software that improves its manufacturing process, it would be possible to license it to corporation $Y$ without reducing the value of that software to $X$ 's own manufacturing process. If this were a tangible asset rather than an idea - say, a special piece of equipment - lending it to $Y$ would necessarily mean that at the same time $X$ could not use it. In cost terms, intangibles often have certain (large)

\footnotetext{
32 LEV, supra note 29, at 12.

${ }^{33}$ Id. at $24-49$.

${ }^{34}$ Id.

${ }^{35}$ Id. at 29.
} 
sunk costs and low marginal costs - it does not cost a lot to duplicate the piece of software or to upload it to a customer's server. Returns to scale may be increasing rather than decreasing as is typical of tangible property. ${ }^{36}$ This is the main reason for the enormous profit potential from intangibles. ${ }^{37}$

A related feature is the flexibility of exploitation that characterizes many intangibles that further increases the profit potential of intangibles. A classic example is a piece of software: a flight simulator, for example, could be transformed to a variety of computer games; an inventory system may be reversed engineered and transformed to a human resources system; and a broadcasting solution may be transformed to online teaching platform. This is a very prevalent practice in the world of software, albeit an extremely simplified one. Assuming that these transformations are less costly than writing new pieces of software, and, of course, rely on an already existing "idea" for which somebody is willing to pay, they represent another dimension of scalability that simply does not exist in the tangible world. An old dining table may be used to craft, say, an "entertainment center," but once transformed it is not a dining table and the full cost of its production are wasted from the dining perspective; this is not the case with reverse engineered software.

The network effect value driver is also related to scale..$^{38}$ Potential benefits from networks increase with the size of the network. Naturally, these benefits will be larger if participants value the size of the network. Most industries or markets where network effects are significant rely considerably on intangibles. These are usually technology and information based markets, where intangibles are central.

The challenges of intangible-based enterprises are not negligible. One value detractor is partial excludability (i.e., the inability of owners of intangibles to defend spillovers, and enjoy the full benefits of ownership themselves). ${ }^{39}$ This feature could be viewed as the "price" or the downside of scalability: intangibles may be easy and cheap to duplicate and expand, yet they are similarly easy and cheap

${ }^{36}$ Id. at 30-34 (referring inter alia to Gene M. Grossman and Elhanan Helpman, Innovation in the Theory of Growth, 8 J. ECON. PERSP. 23, 31(1994) (arguing that purposive, profit-seeking investments in knowledge play a critical role in the long-run growth process, while reviewing models of endogenous technological progress and the lessons they can teach us)).

$\begin{array}{ll}{ }^{37} & I d . \text { at } 33-34 . \\ { }^{38} & I d . \text { at } 34-40 . \\ { }^{39} & I d . \text { at } 43-48 .\end{array}$ 
to copy. Even legally protected intangibles are costly to protect, never really $100 \%$ safe, and their protection eventually expires. Partial excludability creates significant pressure, and costs, on management to protect the intangible and maximize its benefits, and adds to the risk of investment in any development project. ${ }^{40}$

Increased risk is characteristic of intangibles in other ways. The innovation process is acknowledged as inherently more risky than any other thing done by a firm: one may, for instance, invest a lot of resources to develop a drug and fail, or be beaten to a patent by a competitor. Moreover, even once one has succeeded in developing and patenting a drug, there is a risk that a competitor will develop a more successful drug that will secure most of the value in the specific market. ${ }^{41}$ The main driver of the risk is the dependence on the "idea" - what Lev calls the discovery ${ }^{42}$ - which has much more value than any other part in the process (testing, commercialization, etc.). This risk is a value detractor, but, of course, once secured, success is enhanced (and competition potentially depressed), so it can be translated into increased returns. ${ }^{43}$

Finally, unique intangibles do not have markets and hence they are considered nontradable. The lack of markets means lack of the best contribution that markets provide: good information about the traded assets. Also, markets reduce risks by allowing liquidity and leverage (risk sharing) opportunities, both of which are very restricted in the case of intangibles, and therefore increase the risks inherent to these properties. ${ }^{44}$ Now, of course, not all intangibles suffer from these risks similarly, and, of course, many intangibles are traded in reality, yet all three of the above value detractors uniquely affect intangibles, their values and, most importantly for our purposes, the ease and reliability of their valuation.

A tangential, but very real difficulty is the crisis in the field of accounting with respect to financial reporting of intangibles. ${ }^{45}$ Many intangibles are not recorded on the firm's balance sheet and therefore

${ }^{40} I d$.

${ }^{41}$ See, e.g., id. at $48-50$.

${ }^{42} I d$. at 51-54.

${ }^{43}$ See, e.g., id. at 54 .

${ }^{44}$ See, e.g., id. at 55-56.

45 See, e.g., John R. M. HAND AND BARUCh LEV, INTANGIBLE AsSETS: VAlues, MeAsures AND Risks 447-524 (2003); Leandro Cañibano, Manuel García-Ayuso \& Paloma Sánchez, Accounting for Intangibles: A Literature Review, 19 J. ACC. LIT. 102 (2000); Douglas J. Skinner, Accounting for Intangibles - A Critical Review of Policy Recommendations (December 2007), available at http://ssrn.com/abstract=1080572. 
are not reflected in the book value of the firm, which further distorts whatever the market response may be to them. ${ }^{46}$ It also encourages inefficient behavior by management and investors in a firm that operate based on incomplete and asymmetric information. ${ }^{47}$

Next, I explore the importance of these unique and varying assets in the relevant context for transfer pricing purposes: cross-border, intra-group transactions.

\section{Intangibles and MNEs}

MNEs are unique as well. Their prominence in international trade is unquestionable. ${ }^{48}$ Their success is particularly interesting since they have to overcome some obvious basic hurdles such as the costs of expanding operations across borders and the increased agency, monitoring, administrative, and compliance costs of merely operating in a multiple-country setting. ${ }^{49}$

The theory of MNEs and their existence, despite these hurdles, is that in highly uncertain conditions and when a certain investment is very specific to a firm, opportunism is highly likely and therefore internalization can be more efficient than market transactions. ${ }^{50}$ Internalization serves MNEs well when they go abroad, particularly in their choice of the location of the investment and the mode of operation. ${ }^{51}$ The MNE as a hierarchy can save on transaction costs and

\footnotetext{
46 LEV, supra note 29, at 55-56.
}

47 I do not discuss the effect on taxation, yet, since taxation always starts from the financial information, the problematic standards exacerbate the distortion that exists anyway in this context.

48 See, e.g., U.N. CONFERENCE ON TRADE AND DEV., World INVESTMENT REPORT 1999: Foreign Direct INVEstMent AND THE Challenge of DEvelopmEnT, U.N. Sales No. E.99.II.D.3 (1999).

49 See Richard E. Caves, Multinational EnTERPrise and Economic ANALYSIS 1-23 (2d ed. 1996).

${ }^{50}$ This internalization explanation arose in the transaction cost economics movement, not necessarily focused on MNEs. See, e.g., Oliver E. WiLliamson, MARKET AND HIERARCHIES: ANALYSIS AND ANTITRUST IMPLICATIONS (1975); Oliver E. Williamson, The Economics of Organization: The Transaction Cost Approach, 87 AM. J. SoC. 548 (1987); Oliver E. Williamson, The Modern Corporation: Origins, Evolution, Attributes, 19 J. ECON. LIT. 1537 (1981). The analysis was then extended to the international context. See, e.g., D.J. Teece, Transactions Cost Economics and the Multinational Enterprise, 7 J. ECON. BEHAV. \& ORG. 21 (1986).

51 John H. Dunning, Trade Location of Economic Activity and the Multinational Enterprise: $A$ Search for an Eclectic Approach, in THE INTERNATIONAL AlLOCATION of ECONOMIC ACTIVITY: PROCEEDINGS OF A NOBEL SYMPOSIUM HELd AT STOCKHOLM (B. Ohlin et al. eds., 1977), reprinted in JOHN H. DunNING, EXPLAINING 
government interventions (including taxes), and has the ability to overcome or operate despite the inherent difficulty of development of intangible markets. ${ }^{52}$ MNEs survive and thrive because they are hierarchical, which allows them to overcome market imperfections such as the ones mentioned above by efficient internalization.

Intangibles are crucial in the course of maintaining and increasing this advantage, which explains the centrality of intangibles for successful MNEs. ${ }^{53}$ We already mentioned that networks effects are large in intangibles-heavy industries, and these are the same industries where MNEs thrive. ${ }^{54}$ One may argue that intangibles even determine the boundaries of MNEs. ${ }^{55}$ Anyway, intangibles are central among the necessary conditions for the successful operation of MNEs. ${ }^{56}$ The research about MNEs, and the explanations of their existence have significantly advanced in recent years. A consensus has not developed, yet the internalization of costs emerges as a major, if not exclusive, explanation of the MNE phenomenon. ${ }^{57}$ Extension of this debate is beyond the scope of this article, yet this academic research supports the importance of intangibles, both in terms of substance and dollar value for MNEs and the inherent risk and often unavailability of markets for intangibles. ${ }^{58}$

Intangibles are not just important $;{ }^{59}$ they generate significant income for MNEs. Intangibles also generate significant benefits for governments, and such governments struggle with MNEs and between themselves over the taxing rights of the income generated by these intangibles. ${ }^{60}$ Transfer pricing is a key enforcement tool in the hand of governments in our world of tax competition between countries;

INTERnATIONAL PRODUCTION 13 (1988). For a relevant discussion of Dunning's work on MNEs, see Monica Boos, InTernational Transfer Pricing: The Valuation OF INTANGIBLE ASSETS \1.3 (2003).

${ }^{52}$ See, e.g., LEV, supra note 29 , at 55-56.

${ }^{53}$ See, e.g., CAVES, supra note 49 , at 162-188.

${ }^{54}$ See id.

${ }_{55}^{55}$ See Boos, supra note 51, at 30-31 nn.134-37.

56 This is particularly important to horizontally integrated MNEs. See CAVES, supra note 49 , at $4-5,162$.

${ }^{57}$ See, e.g., id. at 1-23.

58 See, e.g., Richard E. Caves, Multinational EnTERPrise and ECOnOmic ANAlysis (3d ed. 2007); JOHN H. DUNNING, Multinational ENTERPRISES AND THE GlOBAL ECONOMY (2d rev. ed. 2008).

${ }^{59}$ See generally MiChELle MARKHAM, THE TRANSFER PRICING OF INTANGIBLES 1-4 (2005).

${ }^{60}$ Jane G. Gravelle \& J. Taylor, Tax Neutrality and the Tax Treatment of Purchased Intangibles, 45 NAT'L TAX J. 77, 81 (1992). 
however, the arm's length standard faces difficulty at the outset because of its fictitious basis. This basis is the attempt to pretend that we can extrapolate market prices when markets may not exist without changes in economic circumstances, and when the mere existence and business success of the taxpayers (MNEs) depends on these circumstances of superiority of hierarchies over markets.

Note that the reality is not as homogenous as the above explanation may imply. Not all intangibles are developed by MNEs and there are markets for certain intangibles, including cross-border arm's length transactions in intangibles. Nonetheless, these transactions often occur because of circumstances under which the MNEs involved expect higher profits from selling or licensing the intangible than keeping the intangible inside the firm. This is the classic situation that a MNE faces when it considers expansion into a new market (i.e., country) while a market transaction alternative exists in the form of, say, an interested local licensee.

The choice between licensing or new foreign investment may be complicated and is affected by many considerations: the size of the new market (if too small the risk may not be worth the benefit), the difficulty and costs of licensing (a bad legal environment and lack of trust or bad communication with the potential licensee can be fatal), and timing (licensing may bring the product to market quickly, while establishment of a new operation may take time that an MNE may not have with certain products), among others. ${ }^{6}$ Arm's length, crossborder licensing of intangibles of this kind, however, does not make the valuation of intangibles easier because these market transactions necessarily differ from the related party transactions even when dealing with the exact same intangible. The differences arguably make these two types of transactions noncomparable as evidenced by the very decision of the MNE, who controls its own decision to license or not, to go one way or the other. Current practice uses adjustments to try and bridge this gap, ${ }^{62}$ but this is an awkward solution since it relies itself on comparables that necessarily do not face the same differences and because it diverts the control from the invisible hand of the market to the experience reliability and other qualities of professional valuators. Whatever one thinks about it, this is not just application of the arm's length standard or a market approach.

Finally, taxes affect the decisions of MNEs, but I wish to neutralize that fact for now, since taxation effects include the effect of

${ }^{61}$ For a good review and analysis, see CAVES, supra note 49, at 168-72.

62 See infra Part IV.A. 
the application of the transfer pricing rules that we are trying to evaluate here.

The next section elaborates on the valuation process itself in light of the challenges discussed in this section to expose the margins of error and accuracy range that we really deal with and which current law basically ignores. This analysis will allow us at a minimum to acknowledge the efficacy of our current law. ${ }^{63}$ Later in the article, it will help us assess it against alternatives.

\section{TRANSFER PRICES AND THE VALUATION OF INTANGIBLES}

Globalization and market sophistication brought about significant advancement in the art of business valuation. This is particularly true to the valuation of intangibles, which is a challenging exercise due to the unique characteristics of intangibles that we have explored in the former section. This section explores the application of general valuation theory and practices to intangibles, maintaining a focus on the context of transfer pricing. This focus is particularly important because one crucial lesson about valuation is that it is a strongly context-dependent practice. ${ }^{64}$ Hence, this section first explains the "valuation" doctrine embedded in our current transfer pricing laws, namely the application of the arm's length standard. Subsequently, the section examines the effectiveness of this doctrine through the lens of the traditional valuation practice and investigates the usefulness of such traditional (and some less traditional) valuation methods for the establishment of transfer prices of intangibles.

I use the term "practice," rather than "science" for instance, since a second important lesson about valuation is that it produces estimations of value, ${ }^{65}$ not value in the colloquial sense. This point is

${ }^{63}$ Another aspect that adds to the complexity of an already quite complex analysis is the fact that intangibles come in various and different forms. Some of them have certain of the characteristic explored in this section and some have others; some are easier to valuate in certain circumstances and some are very difficult. The degree of accuracy (for lack of a better word) significantly varies from one case to another, and accordingly the abuse and distortion potentials vary. A detailed inventory of the various types of intangibles and their unique sets of features and value drivers is beyond the scope of this article. Yet, throughout the analysis I demonstrate the importance of this realization in order to further establish the claim that current law deals with the valuation of intangibles poorly, and therefore does not attain its goals.

${ }^{6}$ See Weston anson \& DONNA SUChy, INTEllectual Property VALUATION: A PRIMER FOR IDENTIFYING AND DETERMINING VALUE 30-31, 138-42 (ABA, 2005); SMITH \& PARR, supra note 27, at 256.

${ }^{65}$ See, e.g., SMITH \& PARR, supra note 27, at 140. 
critical for the purposes of this article because it emphasizes the limitation of valuations that we, in the tax practice, oftentimes treat as facts, ignoring or not fully noting their true nature.

\section{A. The Arm's Length Standard}

\section{Background}

The arm's length standard is the heart, spirit and the foundation of the current international transfer pricing regime. The basic idea of the arm's length standard is that transactions between related parties should be priced as if such transactions were done between unrelated parties and therefore subject to market pricing. The standard arose in the United States in legislation attempting to deal with domestic related party transaction in the early income tax days. ${ }^{66}$ The standard was enacted into law explicitly in a 1935 regulation, ${ }^{67}$ and remained practically unchanged until 1968, when the first modern set of regulations was promulgated. $^{68}$ Cross-border related party transactions were few and did not concern the government until the post-World War II era, which was characterized by expansion of MNEs and cross-border related party transactions.

The government responded with the 1968 regulations, which included specific rules for intangibles and services but only little guidance about the practical application of the rules to these income items. The arm's length standard requires the taxpayer to find comparable market transactions between unrelated parties and imitate their pricing in the related party transactions for tax purposes. The transferor is viewed as if she charged the transferee a transfer price similar to that charged in the comparable transaction, adjusted to the level of difference between the related party and the comparable unrelated party transactions. This is and has always been the essence of the transfer pricing practice. Finding comparables was key under the 1968 regulations, yet the regulations lacked guidance regarding situations where comparables were absent or unsatisfactory. Not surprisingly, MNEs continued to thrive and exploit the weak enforcement of these rules. ${ }^{69}$

66 War Revenue Act of 1917, ch. 63, 40 Stat. 300 (1917). For an historical review, see Reuven S. Avi-Yonah, The Rise and Fall of Arm's Length: A Study in the Evolution of U.S. International Taxation, 15 VA. TAX REV. 89 (1995).

${ }^{67}$ Art. 45-1 of Reg. 86 (1935) (Revenue Act of 1934).

${ }_{68}$ T.D. $6952,1968-1$ C.B. 218 .

69 The tax incentives permitted for investment in Puerto Rico became 
Congress responded this time with the only substantive amendment to section 482 to date, adding to the arm's length standard a "commensurate with income" requirement applicable to payments for the use of intangibles. ${ }^{70}$ This meant that taxpayers could not focus on a one-time battle over an established transfer price and were required to make periodic adjustments, even to an (initially) appropriate transfer price where future income proved insufficient or excessive. Congress further instructed Treasury to study the issue and provide application guidance for the new commensurate with income requirement. The "white paper" of 1988 resulted from this study, ${ }^{71}$ yet the study drew significant critique and it took two rounds of proposed regulations until new regulations were eventually finalized in $1994 .^{72}$

The 1994 regulations attempted to address the shortcomings of prior regulations. They acknowledged that exact comparables do not always exist and filled the gap by the establishment of the concept of arm's length range. ${ }^{73}$ Practically, taxpayers had to establish this range from all reasonable (rather than exact) comparables, and then choose a transfer price effectively from the $25 \%-75 \%$ inter-quartile range. Failing to do that opened the door for the Service to intervene and pick the mean result. In addition, the 1994 regulations installed the "best method rule," "74 which established that there was no predetermined hierarchy between the available methods yet required the taxpayer to defend the transfer pricing method used based on level of comparability and the data available. ${ }^{75}$ The commensurate with income requirement was relaxed somewhat as the Service created safe harbors from its application when certain methods and guidance were used. The requirement had little "bite" and therefore little relevance.

The arm's length standard dictates, first and foremost, a market approach to transfer pricing. Taxpayers are required for tax purposes to put a fictional price on their nonmarket transactions. This "transfer price" must be established based on other market transactions. An adjustment to such comparable market prices may be made to account for the nonidentity of the analyzed market and nonmarket

particularly popular among tax planners for these purposes. See, e.g., cases cited infra Part IV.B.

${ }^{70}$ Tax Reform Act of 1986.

7 I.R.S. Notice 88-123, 1988-2 C.B. 458.

72 T.D. $8552,1994-2$ C.B. 93.

${ }^{23}$ Treas. Reg. \$1.482-1(e) (2006).

${ }^{74}$ Treas. Reg. \$1.482-1(c) (2006).

75 The article elaborates on the methods in infra Part IV.A.3. 
transactions, yet a price produced by a market must be the basis for the analysis. Similarly, the application of the arm's length standard does not have to result in a firm, single number. The law now acknowledges that the proxy nature of transfer prices calls for a range of numbers that may be reasonable. A variety of mechanisms attempt to produce a single dollar figure out of this range because taxes inevitably must be calculated on a single amount of taxable income produced from that figure. ${ }^{76}$

The only clear and firm aspect in this analysis is the reliance on markets and market prices. It reflects a very strong assumption about the efficiency of markets and the "accuracy" of prices produced by them. Another salient aspect of the analysis is the belief in the ability of taxpayers, via professionals in the field, to establish workable transfer prices, i.e., to find and choose among comparable transactions in most cases, to adequately adjust prices when perfect comparable are not available (always...), and reasonably choose a single figure from a range of reasonable transfer prices (the arm's length range).

One's initial response to this statement should be of puzzlement, since these are all excessively strong assumptions. Indeed, the limitations of markets are well known, as is the predictable uselessness of a search for perfect comparables, yet the system continues to be based on these principles. In fact, the arm's length standard is constantly gaining force, and is at the present established as the universal standards of transfer pricing. I elaborate on this development next, yet, before I proceed I should say that, of course, the grim picture of transfer pricing I portray in the above paragraphs is not complete. We will see that in practice the rules themselves increasingly divert away from the arm's length standard, albeit not explicitly. ${ }^{77}$ Nonetheless, the government insists on the continuing prevalence of the standard and maintains it as a leitmotif and primary interpretative guiding principle in the context of transfer pricing. ${ }^{78}$

76 There is an inherent conflict between the valuation mechanisms used in the practice of transfer pricing and the taxation context within which they operate. The invention of the arm's length range concept intended to accommodate valuation since this is what valuation does in business: produce a range of numbers that the business parties can use in their negotiations of prices. Our transfer pricing rules make this leap (skipping the negotiation part) and pretend that a price can statistically (or otherwise) be produced from the range. See, e.g., Hagelin, supra note 12.

7 See discussion supra note 12; infra note 80.

78 For a recent example, albeit in the cost sharing context, see Molly Moses, Musher, McDonald Seek Technical Fixes, Defend Proposed Rules' Arm's-Length Nature, 14 Transfer PRICING REPORT 825 (Feb. 15, 2006). 


\section{Universality}

Transfer pricing rules have recently become extremely prevalent and important to global economic players as more and more countries adopt such rules. ${ }^{79}$ At the same time, there is a strong trend among the countries that adopt transfer pricing laws to base their rules on the arm's length principle. ${ }^{80}$ The universality of the standard is important for several reasons that go beyond its effect on the international tax regime. On one hand, it makes the transfer pricing rules' reliance on the standard stronger, and maybe more difficult to divert from or even "tweak." On the other hand, because an international transfer pricing regime is being erected, it may be possible to make changes and develop a more desirable mechanism in a more effective manner at the multinational level, since the foundation for such discourse is already in place.

Transfer pricing rules are strange (even in comparison to international tax rules in general) in that their substance is completely unilateral. This is strange because their purpose is to effectively divide income between two (or more) tax jurisdictions by setting the transfer price on a transaction, the income generated by which may be subject to tax in these jurisdictions. Still, except for the general expectation to base the rules and determinations on the arm's length principle, countries do not coordinate the substantive implementation of the rules. Increasingly, countries do coordinate the enforcement of whatever rules they employ, and even the documentation, yet the "prices" determined by the countries involved could be very different. If a tax treaty applies, it is likely to somewhat alleviate this problem by requiring one bilateral treaty member to respect its treaty partner's tax authority's "adjustments,"

79 See, e.g., ERnSt \& Young, 2007-2008 Global Transfer Pricing Survey, supra note 8; see also LEVEY AND WRAPPE, supra note 4, at $\$ 180$.

${ }^{80}$ OECD, Transfer Pricing Guidelines for Multinational ENTERPRises AND TAX ADMINISTRATORS, 1-6 (1995), reinforced by ERNST \& YOUNG, 2005-2006 GLOBAL TRANSFER PRICING SURVEYS, supra note 16, at 5 (noting that some countries converge on the principles of transfer pricing, yet they take different approaches to its enforcement); see also Avi-Yonah, supra note 19, at 170 (telling the story of Mexico, which adopted non arm's length based transfer pricing rules and was pressured to adhere to the universal norm by the international community, particularly OECD); Jaime González-Béndiksen, Mexico Amends Transfer Pricing Rules, 97 TNI 27-24 (Feb. 10, 1997).

${ }^{81}$ OECD, Model Tax Convention on Income and on Capital, Apr. 29, 2000, as updated on 15 July 2005 [hereinafter "OECD Model"], article 9. 
arrangement for them to agree on the transfer prices themselves. ${ }^{82}$ The only arrangement that currently does this is a multilateral advanced pricing agreement (APA), which is extremely rare,$^{83}$ time consuming and costly. Most importantly, an APA is initiated and led by taxpayers rather than the involved tax authorities. Advocating a change in approach towards a more cooperative effort at the substantive rules level is a major theme of this article. The scope of this need goes beyond that of this article, ${ }^{84}$ yet I will demonstrate that it is particularly important in the context of valuation of intangibles for transfer pricing purposes, and therefore relevant here.

Furthermore, I am not conducting a comparative study or analysis. I limit my comments and proposals to the U.S. context, yet, since some of the issues are multilateral in scope I elaborate on them to the extent they are relevant to U.S. tax policy. Next, I elaborate on an aspect of the U.S. transfer pricing law that is not universal, and actually departs from the arm's length principle.

\section{Commensurate with Income}

This single amendment to section 482, enacted in 1986 , requires taxpayers in the context of transferring intangibles, to consider the (actual) realized profit from the exploitation of the transferred intangible. ${ }^{85}$ Accordingly, the "original" transfer price - determined before the profit potential was realized, and frequently without sufficient or adequate comparables - must be adjusted to reflect changes in that income. Practically, taxpayers are required to make "periodic adjustments" (normally on an annual basis) so that the transfer price (royalty) would be commensurate with income. ${ }^{86}$

This is, of course, a major deviation from the arm's length

${ }^{82}$ There is a mutual agreement procedure that may reach that result, but it is long, costly, and requires a persistent and powerful taxpayer to convince her government to initiate the procedure. See $i d$. at articles $25,9 \mathbb{\text { I }} 2$.

${ }^{83}$ For example, in 2006 - a productive year for the APA project - the United States concluded only one multilateral APA. See I.R.S. Announcement 2007-31, 200712 I.R.B. 1.

${ }^{84}$ See Brauner, supra note 21.

${ }^{85}$ For a review and a proposal to use the modality of a multilateral APA as the primary device of an international transfer pricing regime, see Eduardo A. Baistrocchi, The Transfer Pricing Problem: A Proposal for Simplification (The Berkeley Electronic Press, Working Paper No. 1228, 2006), available at http:/law.bepress.com/cgi/viewcontent.cgi?

article $=5850 \&$ context $=$ expresso.

${ }^{86}$ See Treas. Reg. \$1.482-4(f)(2) (2006). 
standard, and an unusual deviation from the normal application of the realization principle at the basis of our income tax system. It requires determination of transfer prices based on (actual) income rather than market pricing, and it allows hindsight, ${ }^{87}$ which formerly was ruled impermissible in transfer pricing. ${ }^{88}$ The rest of this section elaborates on the different valuation approaches, including the differences between the income approach and the market approach, but in the interim, one should note that the commensurate with income legislation sends an important message. First, it acknowledges that pure arm's length analysis based on comparables in the tradition of the market approach is not always sine qua non. Second, it emphasizes the importance of transferring intangibles in this context, and the complexity of determining transfer prices for their transfer that require the only special statutory rule we have (the "commensurate with income" addition). It admits, at least in the context of intangibles that good comparables are not always available. Finally, it implies that a unitary approach may not be feasible for a workable transfer pricing regime, so that we may need a variety of rules to deal with the complexity of the transactions involved.

Deviating from the unitary rule or approach itself has serious implications, primarily complexity consequences that are inherent in any legal regime that applies different rules to different situations that are not always easily distinguishable. The key questions are when should the commensurate with income standard apply and when the arm's length standard is sufficient to reach an appropriate transfer price. Leaving the choice to the taxpayers is not a good solution, since they would obviously take advantage of the opportunity to further abuse these rules. The government would not concede, though, that the arm's length principle is no more the single prevailing principle for transfer pricing analysis. The government's solution was to aggressively interpret the commensurate with income standard as if it is subject to the arm's length principle. ${ }^{89}$ The regulations therefore require periodic adjustments only in certain cases when the traditional transfer pricing determination based on comparables is not available. ${ }^{90}$ So, taxpayers that could establish "exact" comparables were not

${ }^{87}$ See, e.g., Kathleen Matthews, Mogle Says IRS Can Retroactively Apply Much Of Transfer Pricing Regs., 93 TNI 89-1 (May 7, 1993).

${ }^{88}$ R.T. French, 60 T.C. 836 (1973).

${ }^{89}$ A controversial contention that was heavily criticized. See, e.g., Andy Yood, API Attacks White Paper for Misguided Policy, Recordkeeping Requirements, and New Penalties, 89 TNI 11-58 (Feb. 15, 1989).

${ }^{90}$ Treas. Reg. $\$ 1.482-4(f)(2)(i i)$ (2006). 
bothered by it. Similarly, inexact comparables may be used without periodic adjustments if certain requirements are met, the primary of which is that actual profits deviation is no more than $20 \%$ from the estimate, based on which the original transfer price was calculated. ${ }^{91}$ Additional safe harbors exist as well. ${ }^{92}$ This doomed, not surprisingly, the commensurate with income standard to its current irrelevance.

The installation of an income approach to a system that is based on a market approach for most purposes was effectively averted through this aggressive interpretation. Yet, this was not the end of it, since comparables were not available to provide solutions to all cases, no matter how little comparability was required. Consequently, further deviation from the arm's length standard took place in the transfer pricing establishment methods permitted by the regulations. Now taxpayers are sometimes required to use non arm's length based methodologies to establish their arm's length transfer prices. ${ }^{93} \mathrm{I}$ will come back to this awkward reality in the conclusion of this article, but first I want to expand a little on the basic tax policy implications of the powerful arm's length standard.

\section{Tax Policy Implications of the Arm's Length Standard}

The evolution and strength of the arm's length standard was primarily due to its practical appeal and the historic context of its adoption. This is not the place for a full analysis of the issue; however, it is important to realize why this standard was adopted and what the advantages of using it are before one begins taking it apart and criticizing some of the detailed rules that evolved from its universal adoption. As previously mentioned, the standard developed in a domestic setting and in a low tech, bricks-and-mortar economy. The potential for abuse in that setting was significantly lower than it is today and there was no risk of tax base erosion (i.e., not only no tax, but no taxable income for which to account). Add to that the belief in the efficiency of markets and the complementary emphasis on commercial competition as a guarantor of perfect markets, and one can understand the appeal of the simple market based methodology. There was no need for complex, subjective calculations and estimations. The "invisible hand" was sufficient. Since the stakes were much lower, it also made sense to have less costly methodology.

\footnotetext{
91 Id.

92 Id.

${ }^{93}$ See infra Part IV.A.
} 
The change in emphasis from domestic to international tax enforcement, and the opening of global markets, combined with the evolution of MNEs and of intangibles as major economic drivers, did not prompt reevaluation of the basis of the system. In fact, our whole tax system develops relatively conservatively. There is a strong preference for change by interpretation, through "massaging" of rules and concepts, and an almost religious belief that old concepts must be good for new realities if we just stretched them in the right way. ${ }^{94}$ Thus, the arm's length principle persisted to become the primary foundation of the system that now needs to deal with a completely different world than the one for which it was adopted.

This reality resulted in an inefficient system. The main message of this article may in fact be that this system has high compliance and enforcement costs. Additionally, this system is very inaccurate and generates an artificial disadvantage to taxpayers who engage in regular cross-border, intra-group transactions. This system particularly disadvantages those who rely heavily on intangibles in their trade. Note that this waste does not mean that the system is inevitably flawed. Such a determination could be made only once it is compared with alternative systems.

Finally, although not a primary concern of this article, the bias in favor of large, international MNEs also has fairness implications. In the United States it seems likely that such implications will not include distribution from the better off to the less well off. ${ }^{95}$ The system also naturally affects inter-nation equity, which is also beyond the scope of this article. ${ }^{96}$

In conclusion, it is difficult to justify the centrality of the arm's length standard in the theory and practice of transfer pricing based on the traditional tax policy analysis measurements of efficiency, equity (or fairness) and administrability. ${ }^{97}$ History and perceived simplicity

${ }^{94}$ For the most notable criticism of this phenomenon, see Michael J. Graetz, The David R. Tillinghast Lecture: Taxing International Income: Inadequate Principles, Outdated Concept, and Unsatisfactory Policy, 54 TAX L. REV. 261 (2001); reprinted in 26 BROOK. J. INT'L L. 1357 (2001).

${ }^{95}$ The study of this effect and its extent will have to wait for another day; however, it will be difficult to argue that increasing large MNEs' profits will result in redistribution from the rich to the poor.

${ }^{96}$ This standard is not an established indicator of good tax policy. It is not even clear what it means and whether it is important.

97 See, Brian E. Lebowitz, Transfer Pricing and the End of International Taxation, 1999 WTD 186-17 (Sep. 27, 1999) (criticizing the arm's length standard and predicting that it is unsustainable and will eventually become extinct). 
probably play a major role in the dominance of the arm's length standard, and its universality fortified its position and made it even more resilient. Against this background, I next explore the traditional valuation approaches to evaluate the soundness, advantages and disadvantages of the current transfer pricing "valuation" methodology based on the arm's length standard.

\section{B. The Market Approach}

\section{The Market Approach to Valuation in General}

The arm's length standard is basically an articulation of the traditional market approach to valuation. ${ }^{98}$ Valuation is a process for estimating ${ }^{99}$ or measuring ${ }^{100}$ the "value" of the subject of the valuation: asset, liability, transaction, business, etc. Value is an elusive concept, since there are various and different contexts of value. Market value is the most common reference but not the only one. ${ }^{101}$ Still, a natural perception is that everything has a single value (or price in our context) and in most cases the different "values" are very similar - if not identical - to each other. Nonetheless, this is not always the case. Some valuation methodologies attempt to establish minimal value, while others target maximal values. Understandably, these would produce very different tax consequences if used.

The market approach to valuation usually targets the fair market value of the subject of the valuation. ${ }^{102}$ It simply uses market transactions to produce or substantiate values or prices in comparable nonmarket transactions. ${ }^{103}$ This is basically what the practice of transfer pricing is currently about: taxpayers are required to establish transfer prices for their related party transactions based on comparable, unrelated party transactions. According to this approach, prices are not "calculated" but observed, relying on the wisdom of the invisible hand in the market.

98 See generally, SMITH \& PARR, supra note 27, at ch. 9 .

${ }^{99}$ Id. at 169 (using the phrase "an indication of value").

100 HUBBARD, supra note 11.

101 ANSON \& SUCHY, supra note 64, at 31-32, 141-42.

102 One should distinguish between FMV as used here, as an economic term, and the accounting concept of "fair value." See e.g., Mark L. Zyla, Auditing Fair Value Measures: What Auditors Need to Know When Working with Valutation Specialists, THE PRACTICING CPA (Oct. 2003), available at http://www.aicpa.org/pubs/tpcpa/ oct2003/auditing.htm.

103 See, e.g., SMITH \& PARR, supra note 27, at 169. 
There are two important assumptions that drive the market approach. One is that the comparables used are substitutable; therefore the prices of comparable assets or transactions should be similar. The idea is that a reasonable buyer would not purchase an asset if she could substitute it for another asset that costs significantly less. The principle of substitutability is completely ignored by our transfer pricing rules. ${ }^{104}$

The second important assumption behind the market approach is that all maximize the value of intangibles, so, for instance, a patented product is optimized to generate the most value in all cases. ${ }^{105}$ If that is true, we can use all market transactions as comparables, not worrying, for example, about comparing maximal and nonmaximal values. This is a reasonable assumption on its face, but if we remember that some intangibles serve as the "glue" of their businesses, ${ }^{106}$ while others are used as goods and other commercially available assets, it is not so clear that all comparable transactions maximize the same values. There may be other considerations within businesses that operate similarly to market imperfections, which are ignored by this approach.

The key step in the process of valuation based on the market approach is to establish proper comparable transactions. ${ }^{107}$ Present sophisticated markets do not usually produce perfect comparables, so the focus of market-based valuation is on finding the best available sufficiently comparable transactions. First, the appropriate market for comparable transactions is identified and defined. Then it is verified that this market has enough arm's length transactions, among which comparable transactions could be identified. Finally, the data about these transactions is collected.

The value of the comparable transaction is then adjusted to reflect the differences between the comparable transaction and the tested transaction. ${ }^{108}$ The exact details of the comparable transactions are explored to determine the level of comparability and possible areas where adjustments should be made. The second determination that the valuation expert must make (after identifying the comparable

${ }^{104}$ The current rules ask only whether the comparable transactions involve similar assets and include similar terms; they do not ask whether they are substitutable.

105 See, e.g., SMITH \& PARR, supra note 27, at 184.

106 See infra text accompanying note 158.

${ }^{107}$ I use transactions as an example for a subject of the valuation process. This is simply an accommodation to our topic, but market valuation similarly applies to single assets, businesses, liabilities, etc.

${ }^{108}$ SMITH \& PARR, supra note 27, at 169. 
transactions) is whether the comparable transactions are good enough (i.e., sufficiently comparable). Next, the valuation expert establishes the level of comparability and determines the proper adjustments, if any, to the comparable value in the process of establishing the estimated value. Understanding that comparable transactions are not identical transactions, valuation experts prefer several comparables that allow them to produce a "range" of reasonable values. This way, their product seems more scientific, it is necessarily less exposed to refute, and provides flexibility to their clients. It is, of course, also truer to the process, which is an art of estimation rather than a scientific plot or arithmetically calculated value. ${ }^{109}$

The market approach to valuation is appropriate when an active and extensive market for transactions identical (or very similar) to the tested transaction exists. Its primary advantage is its reliance on markets that seem objective. It is perceived as relatively more reliable than subjective calculations that rely heavily on human estimations. The market approach is also more direct, since it begins with the comparable value or price, which looks like the desired final product rather than extrapolation of other types of values, such as income or costs. This approach is also somewhat flexible since it could be adjusted over time, if and when additional data become available.

The weakness of the market approach is its very dependence on markets, since there are not always markets sufficiently established to work with (as is often the case with intangibles). It also depends on the availability of reliable data, which may be rare even if an established market exists. Comparability determination requires a lot of information about the asset sold, and firms are very sensitive to the confidentiality of the exact details of their most valuable assets (often intangibles). Since small differences may produce significant value differences, this approach is very sensitive to the availability and quality of the data.

Like other approaches, unbundling (e.g., delineating the value of a piece of software from the value of the hardware it runs on) creates serious application difficulties. This is particularly true when significant adjustments are required, because then one faces multiple levels of potential mistakes and inaccuracies that may go in similar or different directions, without real control of the valuation expert.

Note also that this method is least appropriate in the most difficult cases - those cases that are more likely to be challenged and contentious - because the most unique, complex, and sophisticated 
assets (often intangibles) naturally have fewer and less accurate comparables. Furthermore, even if comparable transactions exist, firms are particularly protective of the relevant information about their intangibles. This information is required to establish comparability and estimate proper adjustments, so frequently data is not available or is insufficient. The relative uniqueness of intangibles and the typical lack of good relevant data present the primary challenges to the efficacy of the market approach to valuation of intangibles. ${ }^{110}$

2. The Market Approach as Applied to Valuation of Intangibles for Transfer Pricing Purposes

One practical limitation on the use of the market approach to valuation of intangibles is that seldom are intangibles separately transferred in market transactions. ${ }^{11}$ They are more often transferred as part of a whole business acquisition. ${ }^{112}$ Moreover, in the few cases when they are separately transferred, the compensation is usually kept confidential and therefore unavailable publicly. ${ }^{13}$ This, of course, means that simple application of the market approach is not possible due to the very limited availability of good comparable transactions and lack of quality data regarding the price of such comparable transactions. ${ }^{114}$

Another, more specific limitation of this approach is its appropriateness in valuing cross-border related party transfers of intangibles within MNEs. ${ }^{115} \mathrm{I}$ chose to mention it in this section rather than the former section because it is directly relevant to the specific transactions that are the subject of this section. The issue is that

${ }^{110}$ See, e.g., LEV supra note 29, at 55-56.

111 See SMITH \& PARR, supra note 27, at 169.

112 Id.

${ }^{113}$ Id. at 170 (providing some examples of the rare transactions where such prices are publicly available).

${ }^{114}$ Cummins equated this difficulty to a Catch-22: "Investors must have information about intangibles to value them; but investors do not have the information they need because intangibles, by their very nature, are extraordinarily difficult to value." Jason G. Cummins, A New Approach to the Valuation of Intangible Capital 1 (FEDS, Working Paper No. 2004-17, 2004) available at http://ssrn.com/abstract=559461; see also id. at 28 (discussing the difficulty of measuring intangibles).

115 The general limitations of the market approach to valuation of intangibles mentioned in the former section still apply when that approach is used for transfer pricing purposes. 
MNEs specifically choose to internalize the costs of and take advantage of their hierarchical structure rather than engage in market transactions, so comparing the transactions of MNEs to transactions by players who choose the market as an efficient transactional medium may be attempting to compare the incomparable. ${ }^{16}$ More soberly, the problem is that the comparable does not and cannot easily factor in this difference between the transactions. We supposedly analyze the tested transactions as if they were less efficient transactions, since in reality rational players chose specifically not to take that road of market transaction. The key policy question is whether this means that we simply cannot use a market approach here or that it is just more difficult to account for the incomparability in these cases, so further adjustments are required. If the latter is the conclusion (the position obviously taken by current law), one must ask whether we can effectively and satisfactorily make such adjustments, and how.

Under current law, which is explored in more detail in the next section, the level of comparability is not taken into account directly. This is so despite it being the most sensitive aspect of the market approach. It is surprising since the difference between an aggressive, yet an acceptable comparable and an unacceptable comparable may be very small and, most importantly, smaller than the difference between the comparable and the tested transfer price. The level of comparability may, however, be taken into account through adjustments to the comparable price, yet these adjustments typically rely on comparability themselves. Note also that the professionals who perform the market-based valuation sell their experience and expertise, particularly with respect to these adjustments. Being conservative cannot therefore win them customer satisfaction, and it is also not necessarily required to establish credibility. There are sufficient degrees of uncertainties within the "reasonable" price ranges, so the clear incentive created by the system is to push the envelope and reach the price that is most aggressive, yet still within the very wide margin of reasonability. ${ }^{117}$

116 Avi-Yonah, supra note 8, at 25-29; see also H. David Rosenbloom, Angels on a Pin: Arm's Length in the World, TNI 2005-7755 (May 9, 2005). Rosenbloom adds an interesting point: in the search for an arm's length price we ignore the fact that market transactions usually are not entirely "rational." This irrationality and market imperfections naturally are impossible for arm's length to capture.

117 See, e.g., Boos, supra note 51, at 88 . There is little economic literature trying to model this incentive, yet the available literature supports the conclusion of this article. See, e.g., Kimberly A. Clausing, The Impact of Transfer Pricing on Intrafirm 
Our transfer pricing rules adopt only the core application of the market approach to valuation (the use of direct comparables). They observe solely market transactions for the various comparables sought after by the permissible methods. ${ }^{118}$ It is worth mentioning that professional valuators use the market approach also in other manners to extrapolate value. They may analyze important market or other unusual events for that purpose. An unexpected patent expiration is one example; securitization of a specific intangible is another. ${ }^{119}$ More obviously, in a more analytical process, the value of intangibles may, sometimes, be extrapolated from the value of the whole business that utilizes the intangible, usually by discounting from such value the values of all other properties. ${ }^{120}$ This is naturally a difficult and very technical process that requires expertise and significant judgment calls during the process. Sometimes, other approaches to valuation are used in combination with a pure market approach in this context if, for instance, the expert determines that these other valuation approaches are preferable in getting to a certain value required in the process. The transfer pricing regulations ignore these important applications of the market approach in the practice of valuation. One may use them as part of her use of the "fourth" unspecified method, ${ }^{121}$ yet, being unspecified, it is not regulated, and no guidance is available. The level of uncertainty regarding its validity may be higher than in comparison to the use of prescribed methods, even if they are less accurate and sophisticated, which naturally factors in the risk assessment of the taxpayer, discouraging its use.

\section{The Cost Approach to Valuation}

\section{The Cost Approach in General}

The cost approach to valuation uses the inputs (expenditure) into the valued intangibles to construct their value assessment. ${ }^{122}$ It is

Trade, in INTERNATIONAL TAXATION AND MULTINATIONAL ACTIVITY 173 (James R. Hines, Jr. ed., 2001); James R. Hines, The Transfer Pricing Problem: Where the Profits Are (Nat'l Bureau of Econ. Research, Working Paper No. 3538, 1990), available at http://ssrn.com/abstract=226838; Chongwoo Choe \& Charles E. Hyde, Multinational Transfer Pricing, Tax Arbitrage, and the Arm's Length Principle (September 22, 2004) (unpublished working paper), available at http://ssrn.com/abstract=600881.

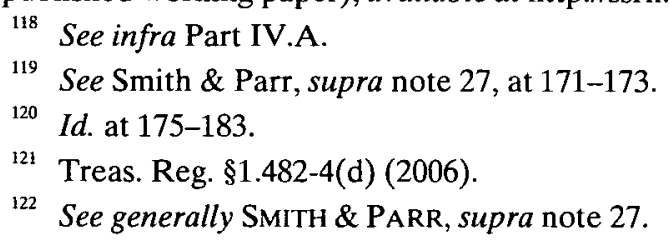


unique in that it is based principally on known monetary values (of these inputs) that are directly related to the tested asset. Data availability is a major strength of this approach, since we usually know the costs of the valuated asset's development, testing, production, etc.

The fundamental assumption behind this approach is that the costs project (and is commensurate with) value. ${ }^{123}$ If the (projected) value exceeded the costs by much, others would enter the market to compete for such extraordinary profits. If value did not exceed costs, rational investors would not engage in such investment.

\section{Application of the Cost Approach to Valuation of Intangibles}

The development of intangibles is, however, a risky business for a variety of reasons, among which information asymmetry is probably the most important. The relationship between costs and the relevant (arm's length) value of intangibles is particularly questionable. ${ }^{124} \mathrm{~A}$ more practical difficulty with this approach is in the choice of costs to be attributed to any particular intangible. ${ }^{125}$

These difficulties with the cost approach are distinctively problematic in the case of intangibles. ${ }^{126}$ Take the classic case of a pharmaceutical MNE. It is typically involved in a large number of drug development projects, only few of which result in a patented drug and even fewer in marketable products. Such enterprises normally have significant costs that are not directly research and development costs - administration, management, legal, advertisement, etc. An obvious difficulty is what portion of all such costs should one attribute to the (few successful) products that require valuation. These include mainly sunk costs that are difficult to attribute to any single product. Opportunity costs are also particularly problematic since they need to be calculated, based not on certain available dollar numbers, but rather on uncertain assessments. Similarly to the difficulties faced by the market approach, the cost approach to valuation of intangibles must rely on estimates, rather than real market prices, for its bases for the valuation - the costs of production (comparable assets/transactions in the market approach's case), which further reduces its accuracy and effectiveness. ${ }^{127}$

${ }^{123}$ Id. at 156.

${ }^{124}$ A key factor in this disparity is the lack of markets for some intangibles. See, e.g., Hagelin, supra note 12.

${ }_{125}$ See, e.g., ANSON \& SUCHY, supra note 64, at 33.

${ }^{126}$ SMITH \& PARR, supra note 27, at 156.

127 Id. 
This is not the sole difficulty, however. First, even though many development projects fail to deliver marketable products they may still produce knowledge or ideas that may assist in the development of other or future products, or even trigger a breakthrough in the development of another product. The measurement, and more problematically the attribution of this contribution is very difficult, if even possible - remember that the valuator is normally not part of the development team, nor does the valuator have any relevant development expertise. Second, it is well known that human capital contributions are difficult to measure and attribute. Think about any technical difficulty that is solved in a trial and error, and brain storming process. The heart of any solution often comes as an "idea" a eureka experience that is clearly a result of many factors involved, including the education and experience of the person who came up with the idea, his or her education, etc., yet how can one distill all relevant factors and attribute the costs involved to the specific solution? If we think about such a scenario, it is easy to imagine why some research and development projects are relatively quick and cheap, while some are very lengthy or costly. At the same time, it is not necessarily the case that costly projects would be successful or result in more valuable outcomes than the cheaper projects. This is the first difficulty mentioned above, which led many to be skeptical about the utility of the cost approach in the context of the valuation of intangibles. I come back to the difficulties later in this section, yet, next I discuss the various practices of valuation based on the cost approach.

\section{The Cost Approach to Valuation in Practice}

The basic questions asked in cost based valuation are how much will it cost to replicate or replace the tested asset. ${ }^{128}$ Note that replacement may mean replacement with an asset that is not identical to the valuated asset, but rather an asset that will be "of equivalent utility," which may mean a less costly asset than the one being tested. ${ }^{129}$

One version of the cost approach therefore takes the historic costs attributed to the intangible asset and depreciates them over the asset's estimated useful life, to produce current value, in current dollars. ${ }^{130}$ Different depreciation methods may be used, as well as different

\footnotetext{
$128 \quad$ Id. at 159.

129 Id.

${ }^{130}$ This method is sometimes called "trended historical costs." See id. at 160.
} 
accounting of the costs - they may or may not be adjusted for inflation, for instance. The fundamental outcome of this approach is a minimal value, yet always meaningful in relation to cost. ${ }^{131}$ It is therefore understandable that in some cases very valuable assets are given relatively low valuation by this approach, and in other cases worthless assets (such as assets driven out of the market by superior competing products) are still considered valuable since they were costly to develop. Such divorce between the valuation and the economic reality results from the failure of the cost approach to take into account any factors that are external or later in time to the development process.

A variation on this method attempts to correct this failure by asking what one would need to spend now (rather than what one has spent in the past) in order to replace, manufacture or reproduce the valuated asset. The advantage of this variation is that it avoids two major uncertainties that valuation based on the cost approach faces: the asset's useful life and the most accurate method of depreciation or trending (stated in current dollars). ${ }^{132}$ This is also a more flexible method. One often asks what the costs would be to produce something other than an exact replica of the valuated intangible that is nevertheless similar enough to replace the intangible (e.g., functionally, monetarily). Note that even under the best conditions the variation is different from the basic method, and results in different values, since it reflects market and technological changes, and, if relevant, actual inflation.

The replacement costs variation may improve the accuracy of valuation based on the cost approach, yet it still always represents a minimum value approach, assuming rationality, whereas the other methods' outcomes may be minimal, maximal or anything in between. This is because we assume that an asset owner would not be willing to sell it for less than the costs of producing it. ${ }^{133}$ Then again, why would one pay more than these costs if she could alternatively just go and produce it herself spending the same costs? Of course, some sellers do sell assets for less than cost, and many buyers pay more than cost because to them it may cost more to duplicate the asset or because the risk of failure in producing the asset is too high (a factor which is

131 See, e.g., ANSON \& SUCHY, supra note 64 , at 33.

${ }^{132}$ The value of the remainder may be a third uncertainty avoided, but $I$ ignore it in this discussion.

133 This is the economics substitution principle. 
critical in the case of intangibles that are so unique in nature). ${ }^{134}$

\section{Assessment of the Cost Approach}

Naturally, the cost approach is best used closest in time to the launch of the product and in simple cases. Once data on income potential is available, its reliability fades since it does not reflect this potential. This is why the historical costs version is often considered inappropriate in our context. The replacement costs version does not fare better because of the uniqueness of intangibles, and the fact that many intangibles are very asset or business specific. This means that they may have little value in circumstances other than the one in which they are used. Any functional replacement may represent significant deviation from the real value of the intangible to the taxpayer who owns it (and is required to establish a transfer price for its transfer).

Finally, coming back to the question whether this approach is appropriate at all, there are competing positions. Farok Contractor views research and development costs as sunk costs that have nothing to do with the final value of intangibles. ${ }^{135}$ So, the potential strength of this method - available data - may end up being its weakness, since it is poorly equipped to generate a good value estimate. Conversely, at least in some cases and with some types of intangibles, it is possible and maybe only possible, to rely on costs as a predictor of value. Think of branding, especially in the context of advertising, or of cohesion of workforce, or management tools, or methods related to experience. In these cases it is likely that costs will be a better predictor of value than in intangibles that require a "eureka" experience; yet, even in the latter cases costs may be relevant to value in some industries. All (legally protected) intellectual properties' values rely heavily on fulfillment of regulatory requirements. Think of human trials or detailed mechanical patenting, etc. Such costs are crucial for the value of the intangible assets, and they may even overwhelm the costs of their "discovery." This, of course, does not mean that they are better predictors of the real value of these intangibles.

Not surprisingly, the value of the cost approach to valuation of

${ }^{134}$ This and other market imperfections are externalities (external to the production of the intangible itself) that cause the price to be different from cost.

${ }^{135}$ Farok J. Contractor, Intangible Assets and Principles for Their Valuation, in Valuation OF InTANGible assets In Global Operations 3-24 (Farok J. Contractor ed., 2001). 
intangibles depends, among other factors, on the types of intangibles valuated. New technological or scientific ideas seem obviously inappropriate for this approach, at least in most industries, and the use of the replacement costs' version does make it better, no matter what adjustments are made. ${ }^{136}$ At the same time, minor improvements of such ideas once in the market seem less unreasonable for this approach, since the fundamental idea had already been established and tried. Branding is another example where maybe the cost approach can be useful. ${ }^{137}$ This is not clearly the case, however, if one thinks of trademarks. The creation costs may have direct relation to the value, yet future costs pose a challenge. It is very difficult to distinguish between maintenance and enhancement costs; the former should not affect the value while the latter should. ${ }^{138}$ In conclusion, the cost approach is not considered appropriate as a primary valuation method for intangibles; it rather serves a secondary role to support value indication in addition to other methods. ${ }^{139}$

In contrast to the input based cost approach the next discussed approach is based on outputs only - the income generated by the tested intangible assets.

\section{The Income Approach to Valuation}

\section{The Income Approach in General}

Value reflects the worth of all future benefits expected from an asset. It could therefore be calculated at any time by discounting these benefits to present value. This is basically what the income approach to valuation does. It uses the expected stream of income from intangibles to determine their (present) value. It discounts this stream taking into account the timing of the expected income and the risk associated with the realization of these expectations. ${ }^{140}$ Successful valuation based on the income approach requires reliable projection of the income stream, its duration and the risk associated with its generation. The better the data is regarding these three factors, the more reliable the valuation will be.

Some intangibles pose significant challenges for this approach,

${ }^{136}$ See, e.g., SMITH \& PARR, supra note 27, at 168.

137 For good examples of the use of the cost approach to valuate trademarks, see id. at 166-167.

${ }^{138}$ For a good discussion see Boos, supra note 51, at 78 n.253.

139 SMITH \& PARR, supra note 27, at 168.

${ }^{140} I d$. at 185. 
since it is not simply a direct income stream that this approach wishes to measure, but rather all the economic benefits of the measured asset. ${ }^{141}$ Some intangibles do not result in a distinct, separate income stream, but rather enhance an existing or another income stream, or generally increases the firm's value or its capacity to generate income. Moreover, some intangibles - (legally protected) intellectual property in particular - are capable of generating extraordinary profits for a period of time, which is not common in our competitive markets. ${ }^{142}$ Hence, the valuation of these intangibles is more difficult and unique than other assets.

A key difficulty of using the income approach in the valuation of intangibles for transfer pricing purposes is that transfer pricing valuation usually takes place in an early stage of the intangible asset's exploitation. Since successful intangibles can get very valuable very fast, which should make their (later) transfer very costly in term of taxation, taxpayers typically plan ahead and establish their structure for tax planning purposes ahead of such time. The result is that the valuation of such assets for transfer pricing purposes must rely on relatively uncertain projections with little or no actual data on the income generated by such assets. Note that this is not the typical situation that valuators face, since typical valuations are in a context of market transactions in "existing assets," assets that are ready for exploitation. ${ }^{143}$ This reality makes their expertise less reliable in our context.

The benefits' projections are the raw material, with which valuation experts craft their product (value), yet income stream projections are sensitive to competing interests within the firm, especially in technology-rich enterprises. This is because of the various effects of too low or too high of a projection on the corporation's short and long-term performance. For example, a corporation raising money normally wishes to inflate these projections to entice investors. Current shareholders also benefit from that because the higher the projection, the higher the value of their stake in the corporation. On the other hand, tax considerations (other than transfer pricing) may pull in the other direction to the effect of shareholders wanting low projections to reflect low valuation of their current stakes in the corporation. ${ }^{144}$ Against this background, transfer

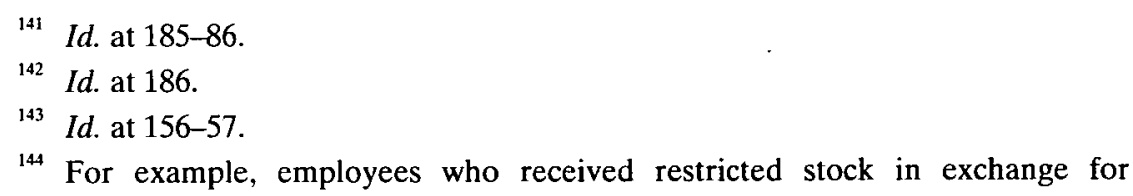


pricing valuation is supposed to get at the "right" price. This sounds good, maybe, in terms of corporate governance and other regulatory purposes, yet, for the purposes of this article, the important point is that external pressure exists to push the boundaries of the appropriate transfer pricing range as far as possible from a comfortable consensus zone. I will get back to this point, yet, next, I discuss the basic operative aspects of using this approach.

\section{The Operation of the Income Approach}

The first step in any valuation engagement, particularly in income based valuation of intangibles, is to clearly identify the subject of the valuation. This is particularly challenging in the context of transfer pricing. On one hand, the taxpayer controls this process and leads the valuation to focus on intangibles transferred within a MNE as identified and intended (and planned for) by the MNE taxpayer. On the other hand, in sophisticated transactions, the taxpayer or the planning advisors may err in the process of identification and isolation of transferred intangibles, which opens the door for the government to argue for valuation of separate intangibles transferred. If sustained, this argument requires reworking of the whole valuation process since intangibles often operate synergistically with other assets that may or may not be transferred at the same time. In addition, the valuation techniques used may need to be reconsidered because the new set of intangibles and the relevant data available may require changing them. Even if the tested intangibles are easily identified, it may be very difficult to isolate income attributed to one intangible from others when such intangibles act in concert together and synergistically, but the transfer pricing rules require us to valuate only

services are not required to pay tax upon receipt of this stock, but rather once the restriction is removed, and then they pay at ordinary income rates. I.R.C. $\S 83(\mathrm{a})$; Treas. Reg. $\S 1.83-1$ (2003). Nonetheless, section 83(b) grants these taxpayers with the option to elect to pay current tax at ordinary income rates on the current value of their stock (even though a realization event did not occur), and in exchange any future value increases will be taxed, when realized, at the preferred capital gains rates. It is not difficult to see that these taxpayers wish to depress the income projections if possible, and by that, the value of their stock upon receipt. Note that other tax rules may create incentives in the other direction. For example, the PFIC rules provide exemption from their disadvantageous effect on the start-up year for corporations if the corporation expects not to be a PFIC in the following two years and indeed is not a PFIC in those years. Optimistic income projections help in this regard, creating an incentive for shareholders at the least to project positive income in the second and third years if they wish to escape being a PFIC. I chose not to elaborate on the complex PFIC rules for the sake of brevity. 
one or a part of them separately.

Indeed, the next step is to estimate the future stream of income or benefits. The most straightforward way of doing it is asking what would be the royalty payment received if the taxpayer were to license the intangible. In order to estimate such royalty stream, a marketbased analysis is required. Similar licensing arrangements are analyzed to compare to the fictional transaction in the valuated intangible. This process is, naturally, subject to all the shortcoming of market-based methods, primarily if good data and similar enough comparables are not easily available.

The valuation expert also often needs to delineate the income attributed (separately) to the valuated intangible from other contributors to the generation of such income, and "clean" all noise. This is particularly necessary and difficult when the intangible is either bundled with other intangibles or tangible properties or operates (to generate income) in interaction with such other properties. Unfortunately (for these purposes), intangibles are often bundled in one way or the other. ${ }^{145}$ In cases where it is difficult to separate the income from the relevant intangible, the valuator may estimate it by estimating the income from the bundled property minus the income that the taxpayers would have generated from the product if it did not have the intangible. This last variation takes into account additional potential value (in comparison to the straightforward royalty estimate), because it takes into account current and, more importantly, future value that could be generated from the interaction of the intangible with other tangible and intangible properties of the taxpayer. ${ }^{146}$

The other elements of an income approach to valuation - timing and risk - affect the discount rate and duration used in the calculation of the present value of the estimated future benefits used. ${ }^{147}$ The difficulty with the timing element is similar in all valuations, and has no particular attributes due to the use in the transfer pricing context. It requires determination of the economic life of the tested asset. ${ }^{18}$ This determination is, again, particularly difficult and subjective when intangibles are considered. ${ }^{149}$ One reason is the

${ }^{145}$ See supra Part II.

${ }^{146}$ This variation is generally more directly related to the taxpayer's business, including potential synergies, growth, etc. in the taxpayer firm rather than what somebody else may be willing to pay.

\footnotetext{
${ }^{147}$ See SMITH \& PARR, supra note 27.

148 See id. at 212.

149 Id. at 219.
} 
uniqueness of intangibles, which makes analogies to economic life of similar assets problematic. ${ }^{150}$ Another reason is the constant change in this area and, moreover, the constant increase in the pace of change (especially in technology, which makes economic life particularly difficult to predict). ${ }^{151}$ Subjective judgment calls and sophisticated modeling help, ${ }^{152}$ yet they increase the level of uncertainty and "inaccuracy," again without any account for transfer pricing purposes. The final component, the risk, is accounted for in the discount rate used, ${ }^{153}$ which, similar to economic life, requires subjective judgment calls, expertise, and a variety of optional models. There is nothing unique in this context either when valuation is performed for transfer pricing purposes.

Beyond the practical difficulties there is the conceptual challenge of identifying "income." Income is not a clear concept - note this is a different notion than income as an income tax term of art - receipts, profits, operating cash flow, etc. may be more realistic and feasible to estimate. Then the question is whether it is pre or after tax income that one wishes to estimate. ${ }^{154}$

\section{a. The Technique of Income-Based Valuation}

There are several techniques that a valuation expert may use to measure the economic benefit of an intangible to a taxpayer. Some are direct in the sense that they measure the benefits generated by the tested intangibles, while others are considered indirect since they attempt to quantify such benefits by reducing them from more general, yet known, ${ }^{155}$ amounts. ${ }^{156}$ Direct techniques include premium pricing - such as the difference between prices of identical products when one is branded and the other is not - and cost savings. ${ }^{157}$ Indirect techniques may be used when intangibles do not directly

\footnotetext{
150 See, e.g., id.

${ }^{151}$ Id. at 220-21.

152 See, e.g., id.

${ }^{153}$ Id
}

${ }^{154}$ Since we perform valuation in the context of this article in order to discover a "price," other taxes are simply separate costs incurred; yet good tax planning views the whole tax scheme, including transfer pricing aspects together, and attempts to incorporate them all to effective tax rate minimization.

${ }^{155}$ One may need to resort to these techniques when direct techniques are not effective, primarily due to lack of good data.

156 SMITH \& PARR, supra note 27, at 186.

${ }^{157}$ See, e.g., id. at 186-92. 
contribute to profitability (or cost savings), or at least when such contribution is more difficult to identify, delineate, and quantify. Synergistic benefits of intangibles such as the ones we nicknamed the "glue" of the corporation, typically require such indirect techniques for their valuation. ${ }^{158}$ Indirect techniques include the relief-fromroyalty method described above, which asks what the taxpayer would need to pay for its use of the intangible had it not owned it already. This method is frequently used in practice since, despite being indirect, it is viewed as an immediate surrogate to a distinct income stream from the tested intangible that is usually not available. The shortcoming of this method is that it relies on either market comparables or rules of thumb and industry standards to establish the appropriate (phantom) royalty rate, which exposes it to all the difficulties that the market approach faces or the obvious inaccuracy of rules of thumb. ${ }^{159}$ On the one hand the market component grants this variation increased credibility, ${ }^{160}$ while on the other hand it exposes it to abuse ${ }^{161}$ since comparables are always approximate and we do not, and probably cannot, accurately adjust them for the level of comparability.

Another indirect method requires comprehensive analysis of the profit margins of a taxpayer (e.g., a corporation), starting with the total earnings of the enterprise as a whole and making adjustments to take into account alternative and complementary investments of the capital of the corporation. This, of course, is a more sophisticated method, yet it relies heavily on the expertise and experience of the valuation expert, who, at the end of the day is a commercial service provider to the taxpayer. Other indirect techniques are essentially variations on the two methods mentioned above. ${ }^{162}$

\section{Assessment of the Income Approach to Valuation of Intangibles}

The income approach usually includes multiple layers of estimates - income or its proxy, useful life, discount (interest) rate - and hence layers of uncertainty are compounded. It is therefore inherently subjective and very sensitive to the accuracy of the estimates (i.e., potentially very inaccurate and somewhat capricious). It is very

${ }^{158}$ Id. at 192. Regarding the "glue" metaphor, see infra note 159 and accompanying text.

${ }^{159}$ See id. at 194.

160 ANSON \& SUCHY, supra note 64, at 35.

${ }^{161}$ Id.

162 SMITH \& PARR, supra note 27, at 192-205. 
sensitive to market and industry conditions. Another major difficulty with the use of this approach goes to the nature of some intangibles that operate as the "glue" of the business rather than as a separately marketable product. ${ }^{163}$ Income from such intangibles is difficult to delineate from the income generated by the business as a whole or from one of its products if the product embeds various intangible and tangible properties. ${ }^{164}$

Despite the difficulties this approach is still viewed in the marketplace as the most appropriate for our purposes. This is because in comparison to other approaches it is more imminent with value. Income is also ultimately the basis for taxation in our income tax system. The reliance on future numbers, even if only estimates, allows better reality perception than reliance on costs, which may have nothing to do with future value of their product (the intangible), or on imperfect "make belief" markets.

The income approach is widely used in the practice of transfer pricing because the required data is relatively available and relatively accurate. It also allows valuators to perform sensitivity analyses (i.e., changing the assumptions and observing the change in results). That analysis provides clients with information about the importance of the various value-driving factors in each case. ${ }^{165}$

\section{E. Other Approaches and Conclusions}

There are quite a few additional methodologies in the market that do not conform to the traditional approaches, yet they are all basically variations on one or several of these approaches. ${ }^{166}$ Some of these methods are practically important since they are frequently used in practice.

Our transfer pricing rules use, by permitting and providing some guidance for, only a fraction of possible valuation methods used in the

${ }^{163}$ These intangibles are neither rare nor unimportant. See, e.g., Cummins, supra note 114 , at $3-6,26-28$.

164 ANSON \& SUCHY, supra note 64, at 34.

${ }^{165}$ Id. at 34-35.

${ }^{166}$ Id.; see also Robert Ackerman \& Elizabeth Chorvat, Modern Financial Theory and Transfer Pricing, 10 GEO. MASON L. REv. 637 (2002) (promoting the use of financial models, particularly the Capital Asset Pricing Model); Elizabeth Chorvat, Forcing Multinationals to Play Fair: Proposals for Rigorous Transfer Pricing Theory, 54 ALA. L. REV. 1251 (2003); Cummins, supra note 114 (discussing method relying on analysts' forecasts to estimate corporate value, not in the context of transfer pricing); Hagelin, supra note 12. 
ordinary course of the practice of valuation. Even the market-based approach on which our arm's length centered permissible transfer pricing methods are crafted is not comprehensively explored. This reality channels all other valuation techniques to the "unspecified" method category, which lacks guidance and therefore is not controlled similarly to the specified methods. Consequently, the regulations leave the important valuation aspects of intangibles for transfer pricing purposes completely exposed to abuse by taxpayers and their advisors. The other side of this reality is that taxpayers face costly choices due to the lack of guidance or clarity about the risks of choosing one valuation avenue rather than another. ${ }^{167}$

The lack of guidance is even more problematic if one takes into account another feature of intangibles emphasized by this article - the fact that they are not a homogenous group of assets, at least from their valuation perspective. We already mentioned some obvious differences that lead to different preferences in terms of techniques used for their valuation. The simplest example is the contrast between commercially available intellectual property (e.g., popular shrink wrap type software) and intangibles that are completely business-specific (e.g., workforce in place). The former is not that different from tangible commercially available assets and the market approach potentially makes sense for their valuation. The latter require much more work from the valuation expert, and the simple application of the market approach contributes little in that process. Furthermore, valuation experts have some generic preferences of methodologies for different standard types of intangibles according to their different unique economic features. ${ }^{168}$ Our transfer pricing rules completely ignore this, and provide no guidance whatsoever on the distinction between types of intangibles, leaving it completely to taxpayers and their advisors. Interestingly, a table of valuation methods preferences for different types of intangibles in a leading textbook notes that the market approach is never the preferred primary approach for intangibles (as defined for transfer pricing purposes). ${ }^{169}$ This, of course, exposes the inadequacy of our arm's length based regime.

The confusion is exacerbated by the lack of comprehension of the

${ }^{167}$ One must understand that the various approaches and techniques do not normally result in similar - or even close - results. See, e.g., SMITH \& PARR, supra note 27 , at 253 .

${ }^{168}$ See, e.g., id. at 259; see also ANSON \& SUCHY, supra note 64, at 186.

169 The unique intangible "goodwill" does have the market approach as a primary method, yet, it is unique, and, note, it is included in the definition of intangibles for transfer pricing purposes. SMITH \& PARR, supra note 28 , at $259<$ ex. $>13.3$. 
product of valuation. ${ }^{170}$ Taxpayers are required to produce a single dollar amount, yet that dollar amount may be a product of very different techniques with very different levels of uncertainties that are all treated essentially the same. ${ }^{171}$ Correcting this failing by requiring further adjustments or statements may not improve the consequences much, while adding significant costs. Yet, the current regime does not even try to correct this failure, resulting in complete lack of control over the taxation of MNEs. The next section explores how taxpayers, the Service, and the courts operate within this tentative legal environment.

\section{The Practice of Transfer Pricing}

Now that we understand better the complexity and difficulty of the task of estimating the value of intangibles for transfer pricing purposes, we look into how this is done in practice. As mentioned, transfer pricing rules became an integral and important part of the international tax regime in the last decade. Not all of these regimes include extensive, separate rules for intangibles, yet most of them recognize the special difficulty that transactions involving intangibles pose. ${ }^{172}$ This section begins with the unique rules developed in the United States, and continues with the challenges and opportunities that these rules present to practitioners in the field. It concludes with the unique and independent manner in which the courts deal with transfer pricing cases involving valuation of intangibles.

\section{A. The Rules ${ }^{173}$}

The government has for a long time acknowledged the unique aspects of transactions involving intangibles. This has resulted in significant changes to the relevant regulations. ${ }^{174}$ The most important

\footnotetext{
${ }^{170}$ Id. at 254 .

171 Id. at 253.

172 Int'l Fiscal Assoc., Transfer Pricing and Intangibles, Cahiers de Droit Fiscal International vol. 92a., 2007.

${ }^{173}$ This article focuses on the transfer pricing rules, yet there are other provisions that attempt to regulate the cross-border transfer of intangibles, and they are discussed in this article when relevant: section 367(d) (regarding a transfer by a U.S. person of intangible property to a foreign corporation in a nonrecognition exchange) and section 936(h) (rules that apply to intangible property in the hands of section 936 (U.S. possessions) corporations. Old section 1491 (1954) (repealed in 1997) was the equivalent of section 367 regarding transfers to partnerships, trusts and estates.

${ }^{174}$ Treas. Reg. $\S 1.482-4$ (2006); Treas. Reg. $\$ 1.482-5$ (2003); Treas. Reg. § 1.482-
} 
changes were made by the 1994 regulations (over the 1968 regulations). Recently, the government further updated some of the rules in final and proposed regulations. ${ }^{175}$ Before we address these recent developments, a quick reminder of the background is owed.

\section{General Rules and the Arm's Length Principle}

The first modern set of regulations was promulgated in 1968. The expansion of MNEs and cross-border related party transactions after world war II era led to the government's revision of the regulations in 1968, which included, for the first time, specific rules for intangibles (and services). Lack of guidance and effective enforcement led to the only substantive amendment to section 482 itself, when Congress added the "commensurate with income" requirement for payments for the use of intangibles. ${ }^{176}$ Congress further instructed the Treasury to study the issue, which resulted in the "white paper" of $1988 .{ }^{177}$ Two rounds of proposed regulations followed, which were eventually finalized in $1994 .{ }^{178}$

The key changes introduced by these regulations were the acknowledgement of lack of exact comparables, and consequently the establishment of the concept of arm's length "range."179 In addition, the 1994 regulations installed the "best method rule." ${ }^{180}$ This meant that no predetermined hierarchy between the available methods existed, yet it required the taxpayer to defend the method chosen based on levels of comparability and data available. The commensurate with income requirement was relaxed somewhat as the Service created safe harbors from its application when certain methods and guidance were used. The commensurate with income requirement has had little relevance since. Next, the current rules are reviewed, including the changes introduced in the recent proposed regulations.

6 (2006); Treas. Reg. \$ 1.482-7 (2004).

${ }^{175}$ See Treas. Reg. \$1.482-7 (2004); Temp. Treas. Reg. \$1.482-4T (2006).

176 Tax Reform Act of 1986, Pub. L. No. 99-514, § 1231 (1986). See text accompanying supra note 65.

${ }^{177}$ I.R.S. Notice 88-123, 1988-2 C.B. 458.

178 See text accompanying supra note 67.

${ }^{179}$ Treas. Reg. § 1.482-1(e) (2006).

${ }^{180}$ Treas. Reg. $\S 1.482-1$ (c) (2006). 
2. The Analysis

\section{a. Scope}

The transfer pricing regulations apply differently to different types of assets, so definitions are important to distinguish between these assets types. With respect to intangibles the regulations chose a very broad definition, specifying a long list of property types in five categories and a sixth "expansion" category for "other similar items." 181 This last category includes assets that derive value from their intellectual content or other intangible properties and not from their physical attributes. ${ }^{182}$ Assets are included in the definition, and therefore treated as intangibles, only to the extent they have substantial value independent of services of any individual. ${ }^{183}$ Therefore, a primary distinction is drawn between intangibles on one hand and tangible property and services on the other hand.

Practically, the difficulty of these distinctions is exacerbated by the nature of intangible assets that are oftentimes bundled with other properties into a final product. The difficulty of unbundling and delineating the value of the tested intangible from the other contributors to value adds to the general complexity of this preliminary scope question. ${ }^{184}$ Another distinction that is mentioned at times is between manufacturing and marketing intangibles, ${ }^{185}$ yet, this distinction has no practical implications, since both are subject to the same rules of transfer pricing. ${ }^{186}$

Despite the broad definition, some important types of assets that are typically viewed as intangibles are not included. Most importantly, the definition does not mention goodwill and going concern. This does

181 The five categories are: (1) Patents, inventions, formulae, processes, designs, patterns, or know-how; (2) Copyrights and literary, musical, or artistic compositions; (3) Trademarks, trade names, or brand names; (4) Franchises, licenses, or contracts; and (5) methods, programs, systems, procedures, campaigns, surveys, studies, forecasts, estimates, customer lists, or technical data.

${ }^{182}$ Treas. Reg. § 1.482-4(b) (2006).

183 Id.

184 In addition to the practical difficulty the rules provide that in some cases if intangibles are embedded in a tangible asset that is transferred, a separate price determination (valuation) of the intangible is not required, yet the intangible should be taken into account for comparability purposes. Treas. Reg. $\S 1.482-4$ (e) (2006) (referring to Treas. Reg. § 1.482-3(f) (1995)).

185 See, e.g., LEVEY \& WRAPPE, supra note 4, , 420.04.

186 There may be implications in the context of cost sharing arrangements that are beyond the scope of this article. See id. at $\mathbb{1} 410$. 
not mean that they escape the application of section 482 , yet the commensurate-with-income requirement and the specific intangible pricing methods may not apply to them as they apply to other intangibles. Interestingly, temporary regulations included language that limited the definition to "commercially transferable interests," language that was dropped in the final regulations as superfluous due to the government's position that only commercially transferable interests are subject to section 482 . Other assets that are not tangible, such as financial assets, are similarly not included in the definition since the focus of the definition is on intellectual property elements rather than the intangible character of assets.

Even though this part of the law seems unsettled, the definitional stage of analysis has not presented a large number of disputes in reality. ${ }^{187}$ We shall return to the consequences of the fuzziness of this definition later in the analysis.

\section{b. Ownership}

Once the scope hurdle is passed, the next step in the analysis is to determine the owner of the intangible in question. This is crucial because under our transfer pricing rules ownership determines who should be allocated profits from the exploitation (or transfer) of the property. ${ }^{188}$ It is particularly complex, however, in the context of intangibles to determine ownership (in comparison to tangible property). This is because one of the key characteristics of intangibles is nonrivalry. ${ }^{189}$ In simple terms, multiple beneficiaries may enjoy economic benefits from rights embedded in the intangible assets under analysis. The scope of these benefits is significantly less limited than in the case of tangible properties and much cheaper and simpler to extend and divide. For example, only one person (in most cases) can enjoy the benefits of sitting on a single chair at any given time, yet essentially infinite number of people may benefit from a cooking recipe at the same time.

The regulations currently solve this problem by considering only the legal owner ${ }^{190}$ as the (sole) owner of legally protected intellectual

${ }^{187}$ The courts were asked in a few cases to interpret the vague definition, holding, for instance, that a hospital management system was an intangible, Hospital Corp. of America v. Commissioner, 81 T.C. 520, 600 (1983), yet an organizational structure of a group was not. Merck \& Co. v. United States, 24 Cl. Ct. 73, 88 (1991).

${ }^{188}$ Temp. Treas. Reg. $\$ 1.482-4 T(f)(3)(i)$ (A) (2006).

189 See supra Part II.B.

190 This is the case under the (intellectual property) law of the relevant 
property, which means that the rights of all other beneficiaries are viewed as specific rights against the owner rather than rights in the intangible. ${ }^{191}$ This rule is retained in the proposed and (2006) temporary regulations. However, the rule is relaxed somewhat by the option to reassign ownership for the purposes of this analysis if legal ownership "is inconsistent with the economic substance of the relevant transaction." $" 192$

If an owner cannot be identified by law (or contract), the owner is determined based on all facts and circumstances, as who "controls" the intangible. ${ }^{193}$ This changes the decision rule for ownership under existing (1994) final regulations. Under the 1994 regulations nonlegally protected intangibles could have had multiple owners (to the extent of the parties' relative exploitation rights). In the absence of such rights, the developer of the intangible - the person who bore the costs and risks of development - was considered the owner. ${ }^{194}$ Only one person may be considered the developer and all other contributors to the intangibles' values are treated as "assistors," that should be compensated. Assistors are compensated as regular contributors or service providers, practically meaning that they cannot share the "upside" or any extraordinary value generated by the tested intangibles. This controversial developer-assistors paradigm was essentially abandoned, shifting the full emphasis of the ownership analysis to determination of legal ownership or economic control. This means that the parties largely control such ownership determination so long as they establish their position in their agreement. ${ }^{195}$ The

jurisdiction

191 This is effective for tax years subsequent to December 31, 2006. Note that this is a significant change in comparison to prior law that treated legally and nonlegallyprotected intangibles differently and allowed for multiple ownership in intangibles. For a good description of prior law, see MARC M. LEVEY \& STEVEn C. WRAPPE, Transfer Pricing: Rules, COMPLIANCE AND CONTROVERSY II 420 at 53-54 (CCH 2001).

${ }^{192}$ Temp. Treas. Reg. $\$ 1.482-4 \mathrm{~T}(\mathrm{f})(3)(\mathrm{i})(\mathrm{A})$ (2006).

${ }^{193} I d$. When a license includes provision of services to be performed by the Subsidiary to the benefit of the parent (intangible owner), a separate allocation in respect of such services is required, and should be analyzed under the so-called service regulations. Temp. Treas. Reg. § 1.482-9T (2006).

${ }^{194}$ Treas. Reg. $\$ 1.482-4$ (f)(3)(ii)(B) (2006). The other person/s with interests in the property would then be considered "assisters," who deserve arm's length compensation for their contribution, yet are not entitled to any additional (residual) profit. If such a person (developer) could not be identified than she will be determined based on all facts and circumstances.

195 And the agreement has economic substance. The Service acknowledged that 
choice is consistently in favor of workable rules rather than theoretically sound rules.

Directly connected to the issue of ownership are the cost sharing rules. ${ }^{196}$ These rules accommodate arrangements between related parties to share the risks (costs) and benefits (exploitation rights) of developing a certain property (particularly if it is an intangible). This article does not separately analyze these rules, although this is a worthy future project. ${ }^{197}$

\section{c. Valuation and Attribution of Profits}

Once ownership or the division of rights to income is determined, transfer prices are required to be established using one of four methods (discussed below) recognized by the regulations for the valuation of intangibles. The taxpayer must use the "best method," based on all the facts and circumstances. ${ }^{198}$ The valuation of the intangible and related payments must be commensurate with the income earned by the Transferee from its commercial exploitation. ${ }^{199}$ These payments are subject to adjustment to ensure that the commensurate with income standard is maintained. No such adjustment is made if the valuation is based on a transfer of the same intangible to an uncontrolled taxpayer under substantially the same circumstances, and if the valuation is based on one of the permissible methods (comparable uncontrolled transaction, profit split, or comparable profit method) provided certain safeguards are met. Included amongst these safeguards is the requirement that actual aggregate profits vary by no greater than $20 \%$ of the anticipated profits from the use of the transferred intangible.

As already mentioned, the Service has not strictly enforced the commensurate with income requirement. This presents conceptual and practical difficulties that have yet to materialize into a clash between taxpayers and the government. The potential for such a clash still exists. In effect, this standard requires the use of hindsight that conflicts with the concept of price (determined ex ante) and the arm's length principle (that is based on market pricing, and market risks

\footnotetext{
in the preamble to the 2006 temporary regulations. T.D. 9278, 2006-34 I.R.B. 256.

${ }^{196}$ Treas. Reg. \$1.482-7 (2004).

197 The rules, and consequently these cost-sharing arrangements were extremely tax advantaged and therefore became very popular in tax planning, although note that recent regulations attempt to stop some of their abuse.

198 Treas. Reg. \$1.482-1(c) (2006).

199 I.R.C. $\S 482$.
} 
without the benefits of hindsight). Commensurate with income must mean that the Service shall revisit the appropriateness of a transfer price from time to time in light of actual income streams, yet no guidance or clear rules exist about how that shall be done. Literally, this requirement allows the government to become a partner in a transaction at will, enjoying unexpected success, but not failure. This is a major departure from the usual position of the government in our tax system. Indeed, the 1988 white paper explicitly acknowledged the difficulty of reconciling the commensurate with income requirement with the arm's length standard. ${ }^{200}$

The white paper attempted to deal heads on with some of the most important difficulties of transfer pricing enforcement, yet it faced strong criticism, and resulted in (two rounds of) regulations that left many of the difficulties unresolved. The government attempted to maintain flexibility in its enforcement of section 482 . Flexibility, however, has another side, resulting in a de facto decline of the commensurate with income requirement's importance and effectiveness.

\section{The Intangibles Methods}

The 1994 regulations established the current set of acceptable, distinct transfer pricing methods for intangibles that a taxpayer must use. ${ }^{201}$ All of these methods are subject to the general transfer pricing application principles: the requirement to use the "best method" ${ }^{202}$ in each case; the guidelines for comparability analysis ${ }^{203}$ and the provision about establishment of an arm's length range. ${ }^{204}$ In addition, these methods must produce an arm's length price that is "commensurate" with the income attributable to the intangible. ${ }^{205}$

\section{a. The Comparable Uncontrolled Transaction ("CUT") Method ${ }^{206}$}

This is the classical arm's length method. The transfer price is established based on a price charged in a "comparable uncontrolled transaction." This is a parallel method to the tangibles' comparable

\footnotetext{
${ }^{200}$ I.R.S. Notice 88-123, 1988-2 CB 458.

${ }^{201}$ Treas. Reg. \$1.482-4(a) (2006).

${ }^{202}$ Treas. Reg. \$1.482-1(c) (2006).

${ }^{203}$ Treas. Reg. \$1.482-1(d) (2006).

${ }^{204}$ Treas. Reg. $\$ 1.482-1$ (e) (2006).

${ }^{205}$ I.R.S. § 482; Treas. Reg. § 1.482-4(a), (f)(2) (2006).

206 Treas. Reg. § 1.482-4(c) (2006).
} 
uncontrolled price ("CUP") method, ${ }^{207}$ adjusted for the fact that with intangibles it is rare to have comparable transactions with similar enough properties. Its emphasis is therefore on the nature of the transaction: term, rights transferred, etc. ${ }^{208}$ The similarity of transferred property is also important, yet, the regulations project understanding that it may be a less of a factor than in the case of tangible property. In order for intangibles to be comparable, they must have similar profit potentials and they must relate to the same types of products or processes within the same markets. ${ }^{209}$ Again, the functionality rather than simple, actual sameness is important.

Two types of adjustments to the price are required. First, the regular adjustments to reflect level of reliability (or really comparability), which normally take place in the construction of the arm's length range. ${ }^{210}$ Second, to adhere to the commensurate with income requirement that is specific for intangibles, periodic adjustments are required to adjust to the change in circumstances and potentially to data reliability (and availability) changes. ${ }^{211}$

In general these adjustments are left to the expertise of the evaluator since the standard for these adjustments is to take into account all facts and circumstances. Adjustments, however, are allowed only if CUT is indeed the best method, so, for instance, the circumstances of the compared transactions are similar enough ("substantially the same" in the language of the regulations), and only if the differences that exist are minor and have a definite and reasonably ascertainable effect on the price. ${ }^{212}$

CUT is the most direct method to apply the arm's length standard and despite the reluctance of the regulation to establish hierarchy between the transfer pricing methods, the regulations indicate the CUT's method superiority when it is possible to use it. ${ }^{213}$ It is, of course, also the most direct application of the market approach to valuation in this practice. Similar to other market based methods, it is highly sensitive to the availability, reliability, and completeness of relevant data.

${ }^{207}$ Treas. Reg. $\S 1.482-3(\mathrm{~b})(1995)$.
${ }^{208}$ Treas. Reg. $\S 1.482-4(\mathrm{c})(2)(\mathrm{iii})(\mathrm{B})(2)(2006)$.
${ }^{209}$ Treas. Reg. $\S 1.482-4(\mathrm{c})(2)(\mathrm{iii})(\mathrm{B})(1) \quad(2006)$. Note that the former requirement essentially requires the use of the profit based valuation (net present value of profits or future "benefits" from the property) in the analysis.

${ }^{210}$ Treas. Reg. $\$ 1.482-4(\mathrm{e})(2006)$.

${ }^{211}$ Treas. Reg. $\S 1.482-4(f)(2)$ (2006).

${ }^{212}$ Treas. Reg. $\$ 1.482-4$ (c)(2)(ii) (2006).

${ }^{213} I d$. 
This is quite apparent from the examples that the regulations use to demonstrate the application of this method. ${ }^{214}$ Not surprisingly, in practice the importance of this method has been marginalized. ${ }^{215}$

\section{b. Comparable Profits Method ${ }^{216}$}

The goal of the Comparable Profits Method ("CPM") is to evaluate the transfer price charged based on "objective measures of profitability" derived from market transactions in similar circumstances and similar business activities. Specifically, the transferred intangible's value is determined by comparing the profit (operating income) that the tested party (the controlled transferor or transferee of the intangible) generates from such intangible with the profit levels (operating income) of the comparable uncontrolled parties.

This is a statistical method in the sense that it does not use single comparable transactions to establish an arm's length prices, but rather uses similar types of transactions to generate profit levels. The tested party is usually the least complex of the related parties and the one that posses assets that make it directly comparable. ${ }^{217}$ Similarity is determined based on a set of "profit level indicators."

${ }^{214}$ Treas. Reg. $\$ 1.482-4(c)(4)$ (2006). The first example describes the licensing of a patent to producers in essentially identical and neighboring countries, when in one it is licensed to an unrelated distributor and in the other to a subsidiary. This is, of course, a very unrealistic example since it is so narrow. The first example is also useless because one would imagine that a patent holder is likely to make similar business decisions in the processing of penetrating two identical and neighboring markets such as those described in the example. Hence, even if the circumstances described in the example were realistic, it would typically not make much sense to operate in one country through a subsidiary while licensing to an unrelated partyproducer in the other. Example 2 emphasizes how limited the first example is by warning that if in one of these identical countries the incidence of the relevant disease is much higher than in the other then CUT could not be used even in this case. The third example simply explains the application of the interquartile mechanism for the establishment of an arm's length range, and the fourth example states that licensing of similar drugs may not be comparable if their profit potential is different - because one faces competition in its market that the other, being superior to others, does not face. It is easy to see that the examples do not serve to promote the use of CUT - rather the opposite. Furthermore, they provide no insights about the actual process of assessing comparability reliability and adjustments.

\footnotetext{
${ }^{215}$ LEVEY \& WRAPPE, supra note 191, at $\$ 440.01$.

216 Treas. Reg. § 1.482-5 (2003).

${ }^{217}$ Treas. Reg. $\$ 1.482-5(\mathrm{~b})(2)(2003)$.

${ }^{218}$ Treas. Reg. $\$ 1.482-5(\mathrm{~b})(4)$ (2003).
} 
indicators are various ratios of profits, costs, or resources that may provide information about businesses. An important factor in the choice of profit level indicator used is the availability and reliability of data to support the calculation of the ratios. ${ }^{219}$ The regulations indicate that the ratio used should be the one that best indicates the profit level that the tested party should earn, yet there is very little guidance provided to explain how one should go about making this choice of ratio. The implication is that practicality trumps relevance and of course accuracy in this context. The regulations mention specifically the rate of return on capital employed, i.e., the ratio of operating profit to operating assets. Naturally, one must be able to value operating assets for this purpose. ${ }^{220}$ This is the exact thing we are trying to derive in the case of valuation of intangibles for transfer pricing purposes, which makes this ratio useless in most relevant cases. The regulations go on to mention financial ratios ${ }^{221}$ as appropriate in cases when there is close functional similarity between the tested transaction and the sources of the statistical comparable information. ${ }^{222}$ The regulations add that the composition of operating expenses is important if these ratios are used. Both of the above sensitive points (functional similarity, and composition of operating expenses) are likely to be problematic in the case of intangibles, because intangibles are inherently unique in many cases, and, more importantly, it is likely that the data about these factors will be particularly unavailable and unreliable for intangible heavy enterprises. The one example in the regulations that refers to intangibles does not deal with any of these difficulties that are unique to intangibles. ${ }^{223}$

Anyway, profit ratios are used to establish the profit relationship between the tested and uncontrolled party. Relevant considerations in determining whether an uncontrolled party is comparable include cost structures, internal processes, management, market risks, assets, and resources. Adjustments must be made to the profit indicators to account for any significant differences between the tested and comparable uncontrolled party. ${ }^{224}$

Targeting comparability of profit levels and types of transactions

219 Id.

220 Treas. Reg. $\S 1.482-5(b)(4)(i)(2003)$.

221 Such as operating profit to sales and gross profit to operating expenses.

222 Treas. Reg. $\$ 1.482-5$ (b)(4)(ii) (2003).

223 Treas. Reg. $\$ 1.482-5$ (e) ex. 4 (2003).

${ }^{224}$ Treas. Reg. $\S 1.482-5$ (c)(2)(iv) (2003). 
rather than actual prices in actual specific transactions makes this method more feasible then CUT, yet the CPM method is further removed from a model application of the arm's length standard. The CPM method essentially ignores the unique characteristics of intangibles that make them more difficult to value under this and other methods.

\section{c. Profit Split Method ${ }^{225}$}

This method tests whether the allocation of the combined operating profit (or loss) between the related parties is at arm's length. The taxpayer must first identify the most narrowly defined business activity that includes the tested transactions (with respect to which reliable data is available). Then the taxpayer must allocate the combined operating profit (or loss) from such business activity between the related parties. This allocation must then be compared to allocations of profits between unrelated parties in similar circumstances, to test for appropriateness.

The regulations permit two versions of this method. ${ }^{226}$ Comparable profit split simply observes the percentages of profit allocated between unrelated parties and applies these percentages to the transactions between related parties, when and if appropriate. ${ }^{227}$ Adjustments may be made for any differences between the tested parties and the parties in the comparable market transactions, and this method can be used even if differences are material so long as the adjustments can be made. ${ }^{228}$ In practice, this method is very similar to $\mathrm{CPM}^{229}$ The second version, the residual profit split method, allocates the profit first to "routine contributions" of the parties to the relevant business activity, which assumes that attributing simple (normal) profit to such contributions is a relatively simple process. Next, the residual profit (not allocated to routine contributions) should be divided between the parties according to the value of their contributions to the relevant business activity. ${ }^{230}$ The regulations use the case of contributing intangibles as an explicit and primary example of nonroutine contributions that may explain the existence of residual profits. Note that the value of such intangibles contributed is also

\footnotetext{
${ }^{225}$ Treas. Reg. \$ 1.482-6 (2006).

${ }^{226}$ Treas. Reg. $\$ 1.482-6$ (c) (2006).

${ }_{227}$ Treas. Reg. $\$ 1.482-6$ (c)(2) (2006).

228 Treas. Reg. $\$ 1.482-6$ (c)(2)(ii)(B)(2) (2006).

229 LEVEY \& WRAPPE, supra note 175 , at $\$ 350.02$.

${ }^{230}$ Treas. Reg. $\S 1.482-6(c)(3)(i)(B)(2006)$.
} 
required to be determined, and the regulations provide several proposals on how to make such valuations: external market benchmarks that reflect the intangible's fair market value; capitalization of development costs; etc. ${ }^{231}$ This, of course, ignores completely the very difficulty of making such valuations. This Service acknowledged this difficulty, which led to the recent issuance of temporary regulations that attempt to clarify the use of this method. ${ }^{232}$ The temporary regulations disconnected the allocation of the residual profit from the contribution of intangibles; yet, the regulations still do not provide much guidance on how to value the contributed intangibles, if they represent the nonroutine contributions. Similarly to CPM, the profit split method does not seriously deal with the particular difficulties that intangibles present. It mentions methods that may be good for the valuation of intangibles if they are contributed as part of the productive activity tested and if they are nonroutine, yet even then there is no guidance about how exactly to use the mentioned valuation methods or when to use each methods, etc.

\section{d. The Fourth Method ${ }^{233}$}

Taxpayers are not limited to the methods specifically prescribed by the regulations. They may use unspecified methods so long as they comply with the general arm's length requirements (best method, comparability, etc.). ${ }^{234}$ A general requirement for this method is to specify what were the taxpayer's alternatives to its choice of related party transactions, for example prices offered by unrelated parties. ${ }^{235}$ A specific example in the regulations describes a U.S. company that licensed a foreign subsidiary a proprietary process to manufacture a certain product for the European market. The European market price for the product is $\$ 550$ per ton and the stated royalty is $\$ 100$ per ton. ${ }^{236}$ In evaluating the royalty under section 482 , one possible method, subject to the best method rule, is to determine the profit that the U.S. company would have realized if it had manufactured and sold the product into the European market directly. Because the U.S. company's foregone profit was $\$ 250$ per ton, the regulation concludes

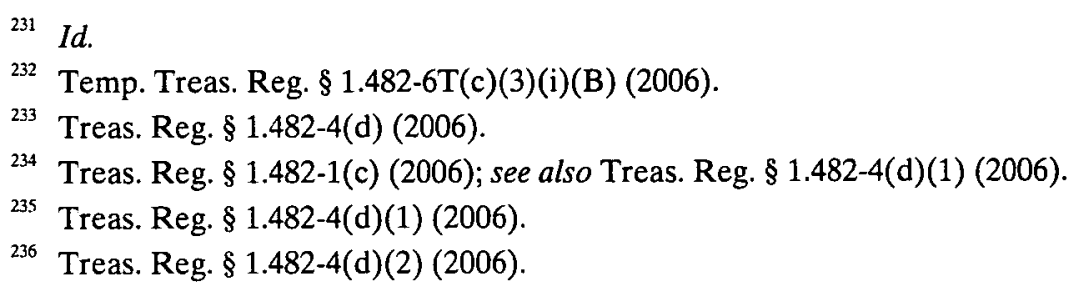


that the $\$ 100$ royalty was not arm's length.$^{237}$ Note that this is just manipulation of the cost plus method that was excluded from the permissible methods for intangibles.

\section{e. Conclusion}

In conclusion, the current regulations specify a unique set of methods for the determination of transfer prices for intangibles; yet, the regulations fail to account for the unique features of intangibles that justify their unique treatment. Only CUT, an essentially irrelevant method, represents understanding that direct comparables are generally not available for intangibles. There are very few examples in the regulations and none of them are helpful in understanding what is different about intangibles and how the permissible methods adjust the traditional (tangible property transfers) analysis to more sophisticated transactions that involve intangibles. Next, I analyze the manner by which the courts have applied these rules. The struggle of the courts in the few transfer pricing cases where they were asked to do determine the value of intangibles blatantly demonstrates the inadequacy of current rules.

\section{B. In the Courts}

The practice of transfer pricing for intangibles, particularly the valuation of intangibles for transfer pricing purposes, are not issues visited by the courts frequently. Only in the mid-1980s, we begin to see relevant cases appear and decided by the courts. It also seems that this increase in cases began to subside towards the end of the millennium. This section reviews and analyzes the courts' positions as they emerge from a few relevant major cases. ${ }^{238}$

\section{CIBA-GEIGY Corporation ${ }^{239}$}

This landmark Tax Court case signaled a new approach in the tax court to these types of cases. Geigy-Basle, a Swiss corporation, established a U.S. subsidiary ("the taxpayer") and licensed to it the right to manufacture and sell two chemical herbicides in the United States, the royalty paid being $10 \%$ of sales.

237 Id.

${ }^{238}$ For a concise, yet more comprehensive listing of transfer pricing cases involving intangibles, see LEVEY \& WRAPPE, supra note 4, at 154-56.

239 CIBA-GEIGY Corporation v. Commissioner, 85 T.C. 172 (1985). 
The government challenged the royalty based on two alternative theories, the first being that the taxpayer and Geigy-Basle engaged in a joint venture that involved the research and development of the two licensed chemicals. Based on the joint venture theory, the parent and the taxpayer were joint owners of the patents on the two licensed chemicals; therefore, each party had the right to manufacture and sell the chemicals, and no royalty payment to the Swiss parent was appropriate. ${ }^{240}$

In the alternative, the government asserted that the $10 \%$ royalty was excessive and not arm's length. Both the government and the taxpayer submitted to the court transactions that they considered comparable to support their respective positions on this point. The court rejected the taxpayer's proposed comparable transaction based on the fact that in the comparable transaction the licensee purchased an herbicide at a mark up from a related person, as opposed to manufacturing the chemical itself. The court found that the lower levels of capital investment and risk borne by the licensee in that transaction made it an inappropriate comparable. The court rejected the government's comparable transaction as well on the basis of a lack of evidence in the record that the circumstances at the time the licenses were granted were sufficiently similar.

The court then turned to independently asses an arm's length royalty. It utilized a relevant factors test prescribed by the regulations. ${ }^{241}$ The first factor considered was a competing offer for the license of the herbicides that was in excess of the royalty rate paid by the taxpayer. The next factor considered was the potential profitability of the herbicides. The court considered independent research reports that the herbicides were superior to all herbicides currently available in the market. The next factor considered was the prevailing rates in the industry, these being between $3 \%$ and $6 \% .{ }^{242}$ The court found that given the superiority of the licensed herbicides they did not constitute average products. The court went on to consider a $25 \% / 75 \%$ rule-of-thumb profit split between licensors and licensees, and found that the taxpayer was retaining approximately

${ }^{240}$ There was no documented joint venture agreement to support the government's first theory. The court did provide for an allocation to the taxpayer to compensate it for some limited services performed for its parent based on Temp. Treas. Reg. \& 1.482-9T (2006).

${ }^{241}$ Treas. Reg. $\$ 1.482-2(d)(2)$ (2006).

${ }^{242}$ A fourth factor considered by the court was the initial investment required of the taxpayer under Treas. Reg. $\$ 1.482-2(d)(2)(i i i)(h)(2006)$, noting that the taxpayer made a considerable investment, but this investment led to considerable profits. 
$80 \%$ of the profits from its sales of the herbicides. Based on the above factors, without attributing decisive power to any of them, and without meaningful discussion of precedents, the court concluded that the existing $10 \%$ royalty rate was at arm's length.

Note that the court accepts the taxpayer's transfer price while rejecting the very basis for it (the taxpayer's comparable transaction). The court carries no deference to the Service, and does not accept its position despite the failure of the taxpayer to meet the burden of proof. The court entrepreneurially engages in independent valuation that convinces the court to eventually accept the "number" (remember, the "price" used by the taxpayer was rejected when the comparable transaction the taxpayer relied upon was rejected) used by the taxpayer.

The court's valuation has several interesting features (that we shall evaluate later in this article):

(1) It is not systematic, but rather uses an anecdotal multifactor test, and further, even when making a determination, the court refrains from providing guidance about priorities or order in the application of this multifactor test;

(2) The court does not engage in an arm's length based assessment, and ignores the comparability-based "valuation methods" prescribed in the transfer pricing regulations;

(3) The court does not meaningfully discuss any precedence or other legal sources;

(4) The court does not engage in a "scientific," numerically-heavy valuation or any other calculation;

(5) The court seems to heavily rely on standards - industry standards and rule-of-thumbs.

We shall see that this is not an isolated case, and that consecutive cases partly follow this attitude.

\section{Eli Lilly ${ }^{243}$}

Eli Lilly, a U.S. pharmaceutical company, set up a subsidiary, Lilly P.R., in Puerto Rico. Patents for pain medications, and know how related to their manufacturing, were transferred to Lilly P.R. in a nonrecognition transaction. Lilly P.R. then manufactured the medications, sold them to Eli Lilly, who in turn marketed and sold them throughout the United States There were significant tax

${ }^{243}$ Eli Lilly v. Commissioner, 84 T.C. 996 (1985), aff'd in part, rev'd in part and rem'd, 856 F.2d. 855 (7th Cir. 1988). 
advantages to operating in Puerto Rico at the time, including an exemption from local taxation for Lilly P.R and exclusion of its income from that of its parent, Eli Lilly. The government attributed all of the income related to the intangibles to Eli Lilly, and limited Lilly P.R.'s income to that of a contract manufacturer (ignoring the transfers above).

The court rejected the government's attribution, as unreasonable ${ }^{244}$ and turned to address the transfer price of the medication. The court determined that the Service may make appropriate allocations under section 482 because there was a distortion of income between Lilly P.R. and Eli Lilly. It found that the failure to include a royalty, lump sum payment, or cost sharing agreement as part of the intangible transfer to Lilly P.R. is a relevant consideration, and that the transfer price did not allow Eli Lilly to earn sufficient profits to fund a proportionate share of its ongoing research and development costs. The court went on to say that had Eli Lilly been dealing with a third party, the failure to receive arm's length consideration (such that it would be able to fund its ongoing research costs) on the transfer of the intangibles to the third party, would have resulted in lower prices on the transfer back (to Eli Lilly). However, the court held that the Service's reallocations were unreasonable and therefore the court made its own determination of the proper allocation of income from Lilly P.R. to the taxpayer.

Because the court found that the transfer price (paid by Eli Lilly to Lilly P.R.) should be lower to reflect the absence of a royalty payment (paid to Eli Lilly), the court continued to independently valuate the intangibles here. It separated the analysis to two periods. First, regarding 1971 and 1972, Eli Lilly suggested the resale price

${ }^{244}$ Under the arbitrary, capricious and unreasonable standard, and first issue discussed was whether section 482 allowed the government to disregard the section 351 intangible transfer. It was answered in the negative. Section 482 can apply in circumstances of a section 351 transfer if required to clearly reflect the income of the parties to the transfer. The court then reviews two circumstances where section 482 may apply, the first being a section 351 transfer followed by an immediate disposition of the transferred property, National Securities v. Commissioner, 137 F.2d 600 (3d Cir. 1943), and the second being a section 351 transfer that effectively separated the property's income from it's associated expenses (e.g., the sale of a sugar crop to a subsidiary prior to harvesting). Central Cuba Sugar v. Commissioner, 198 F.2d 214 (2d Cir. 1952). Neither of these were applicable here. As a consequence the court goes on to state that the Commissioner has no authority under regulation 1.482 2(d)(2)(i) to disregard the intangible transfer. The court then concluded that the government's allocation failed to include in Lilly P.R. income any amount related to the transferred intangibles and therefore it was arbitrary/capricious. 
method, stating that the discounts Lilly P.R. granted on its sales to Eli Lilly permitted Eli Lilly to earn an appropriate mark up upon resale. Eli Lilly's experts based their arm's length price determinations on the relative value of the profit generating assets and activities of the two companies. They argued that the trademark rights retained by Eli Lilly were of minimal value in comparison to the patents held by Lilly P.R.; therefore, the bulk of the contribution to profits from intangibles was attributable to the patents owned by Lilly P.R. Thus, Eli Lilly's profits were based on its marketing activities related to the relatively low-value intangible marketing assets (trademark rights). These marketing profits were estimated using Eli Lilly's marketing profits on the sale and marketing of nine other pharmaceutical products. The court rejected this methodology, stating that the resale price method could only be used when the determination of the gross markup percentage was based on that of a reseller that purchased and resold the product in uncontrolled transactions; whereas Eli Lilly used the previously mentioned ratios based on controlled transactions. The government argued for the application of the cost plus method. The court rejected this approach because the government did not attribute any income to Lilly P.R. for its intangibles.

The court decided to adopt the profit split method, and the first step was to identify the appropriate return (based on costs) for both the manufacturing and marketing activities and then to decide on an appropriate allocation of income to the intangibles held by each of Eli Lilly and Lilly P.R. The court found that an appropriate return for manufacturing and marketing activities to be a $100 \%$ mark up on costs. The court then made a number of adjustments to Lilly P.R.'s cost of goods sold and to the operating expenses relevant to the respective activities of both companies. The rest of the profits were split based on the value of the manufacturing and marketing intangibles, with the court considering the superiority of Eli Lilly's marketing to that of other pharmaceutical companies and the fact that the patent was more valuable than the product's associated trademark. Ultimately, the court allocated $45 \%$ of the profits to Eli Lilly's marketing intangibles and $55 \%$ of the profits to Lilly P.R.'s manufacturing intangibles.

Regarding 1973 (the second period analyzed by the court), the parties agreed that the comparable uncontrolled price method be utilized due to the expiration of the patents, and the resulting entry of a number of new competitors into the market. Eli Lilly proposed a comparable transaction and made a number of adjustments that increased the price of that comparable transaction. The government 
proposed a different comparable transaction, which the court rejected noting that insufficient information was adduced about the circumstances of the transaction and that the companies involved in the comparable transactions manufactured significantly less volume of the product than Lilly P.R. The court based its decision on the comparable transaction submitted by Eli Lilly and accepted a number of its proposed adjustments to the original sales price charged in that transaction, which resulted in increases to the price that Lilly P.R. could charge Eli Lilly, except at a lower rate. These adjustments included: an amount to reflect the comparable manufacturers' receipt of free raw materials and free equipment from the licensee, whereas Lilly P.R. was required to purchase its raw materials; an appropriate mark up on the sale of "sample products" that had been transferred at cost; an increase to reflect that Lilly P.R.'s product was of a higher product quality; and an increase to reflect the generous credit terms on sales that were available to Eli Lilly.

Despite the somewhat confused analysis and the different circumstance of the government's insistence on ignoring the nonrecognition transaction, we can see similar pattern following the court's decision in Ciba-Geigy: the court's assumption of an active valuation role, tendency toward non arm's length based analysis (profit split here), no account for the burden of proof, and nondeference to the government. On appeals, the court upheld the decision of the tax court to refuse the government's argument that it could under section 482 disregard the intangible transfer. ${ }^{245}$ However, the court of appeals reversed the tax court's conclusion that the transfer price for the intangibles was not at arm's length.

The court of appeals stated that the tax court's conclusions conflict with holdings that stock of a corporation is by definition arm's length consideration. In addition, it concluded that the lower court took a too restrictive interpretation of the regulations. ${ }^{246}$ The court went on to find that the income earned by Eli Lilly on the marketing and sale of the medications was sufficient for it to fund its ongoing research costs. The court also noted that Eli Lilly had a wide range of options through which research costs could be funded including liquidating investments or borrowing. Otherwise, the court of appeals generally agreed with the price analysis of the tax court. The only

${ }^{245}$ See Rev. Proc. 63-10, 1963-1 C.B. 490 (addressing the issue directly and stating that such a transfer of intangibles to Puerto Rican subsidiaries would be respected under section 482). The court found the Service bound by the representation made in this Revenue Procedure.

${ }^{246}$ Treas. Reg. 1.482-2(d)(2)(i) (2006). 
change the court of appeals made was to deny the lower court's allocation of Eli Lilly's general research and development expenses to Lilly P.R.

The prescribed transfer pricing methods are used solely as part of the rhetoric, while the substantive guidance in the regulations is completely ignored. The courts desire to make justice, even rough justice, in the specific case, based on some feasible methodology. The courts do not consider the implications of the decisions on the development of the law, and show little interest in providing guidance for future cases.

\section{G.D. Searle $e^{247}$}

This was a companion case to Eli Lilly, with similar facts, issues, and basis for the court's decision. ${ }^{248}$ The intangibles here were patents, technical data, copyright rights, and trademarks related to pharmaceutical products. Here the P.R. subsidiary manufactured the products and sold them to independent pharmaceutical wholesalers. The taxpayer (the U.S. parent) aided in securing these sales via a marketing services agreement whereby the subsidiary paid the taxpayer $25 \%$ of sales to promote and market the products. The taxpayer's income decreased by $50 \%$ as a result of the agreement. Similarly to Eli Lilly, the court respected the nonrecognition (pursuant to section 351) transfer of the intangibles from the taxpayer to its P.R. subsidiary, again, rejecting the government's disregard of it. The court found, however, that although the taxpayer received stock equal in value to the transferred intangibles, it did not receive arm's length consideration on the transfer. The court found that any form of consideration would be permissible provided it is a form of consideration that would be used by parties dealing at arm's length. ${ }^{249}$ The court reviewed the taxpayer's considerable ongoing costs of research and development and noted the fact that the intangibles conveyed in the section 351 transaction represented more than $80 \%$ of

${ }^{247}$ G.D. Searle \& Co. v. Commissioner, 88 T.C. 252 (1987).

${ }^{248}$ Both taxpayers formed Puerto Rican manufacturing subsidiaries, and transferred to them intangibles in section 351 nonrecognition ("tax-free") transactions. Eli Lilly's subsidiary manufactured drugs later sold back to Eli Lilly who sold the drugs to wholesalers, whereas G.D. Searle's subsidiary manufactured drugs and sold them directly to independent (unaffiliated) wholesalers. In Eli Lilly, the price that the subsidiary charged Eli Lilly was challenged as well as the royalty/price that should be attributed to the parent. Only the latter price was challenged in G.D. Searle.

Treas. Reg. § 1.482-2(a)(2)(i) (2006). 
the taxpayers' profits and sales. Consequently, the court found that the taxpayer would have required some form of cash payment in connection with a sale of such intangibles to an independent party in addition to stock (noncash producing) compensation. Thus, the court concludes that the taxpayer's income is not clearly reflected and that it is appropriate to impute an ongoing royalty charge in its favor.

The court then proceeded to compute the imputed royalty charge. The taxpayer argued that it had acquired some of the intangibles transferred through independent licensing agreements and that these prior agreements were comparable transactions that support its transfer price. The court rejected these transactions for two reasons. First, the circumstances surrounding the granting of the licenses differed. The comparable transaction involved a license of intangibles from a French company that did not have FDA approval to market the product within the United States. The taxpayer had to obtain FDA approval for the intangibles and the court noted that this involved significant risk to the taxpayer given only a small portion of submissions to the FDA were ultimately approved. However, when taxpayer transferred the intangible to P.R. subsidiary, the taxpayer already had the FDA approval to sell the patented drug and had developed manufacturing know-how. The second reason is that no established market for the intangible existed in the United States at the time of the French license. In contrast, the taxpayer, not its P.R. subsidiary, holds the FDA approval for all transferred intangibles and had the marketing infrastructure to sell the product in an already established market. The court noted that without the approval the value of the intangibles would be substantially diminished.

The court then stated that whether the payable is deemed to be an additional amount for marketing services provided by the taxpayer, or as a payment to the taxpayer for the use of its intangibles (the "marketing" intangibles), or as a royalty payment in connection with the transfer of intangibles, the result is the same. Then the court without any analysis, but indicating that its decision was based on the record, found that a royalty rate of $25 \%$ of the subsidiary's net sales was appropriate.

Note again, the tendency to avoid detailed analysis or calculations, and to rely on what is perceived by the court as fair arbitrary approximation. Also, note the divorce of this decision from the information provided by the parties and their arguments. Finally, note that the courts do not spend much time on the fiction of comparability - since exact identity cannot be found they simply ignore the basic application of the arm's length principle. They do not 
stop to deal with what comparables are "similar enough" for these purposes; they simply go on to use other methodologies.

\section{Bausch \& Lomb $b^{250}$}

The taxpayer, a U.S. corporation, created a subsidiary, B\&L Ireland, and licensed to it a nonexclusive license to use patented and unpatented manufacturing technology and trademarks for the manufacture and sale of contact lenses worldwide for a royalty of $5 \%$ of sales. The technology enabled the manufacture of contact lenses at costs significantly below that of competitors ( $\$ 1.50$ versus $\$ 4.50)$. The vast majority of sales by $B \& L$ Ireland were made to the taxpayer (at a price of $\$ 7.50$ per lens), who then marketed and sold the product in the United States. The Service assessed and asserted that B\&L Ireland was essentially a contract manufacturer whose sales were assured and who was subject to minimal risks. Thus, B\&L Ireland should be allocated only its costs and a reasonable mark-up. The tax court rejected this determination, concluding that B\&L Ireland was subject to market risks and as such, it could not be characterized as a contract manufacturer. ${ }^{251}$ Based upon this determination, the court decided, against the government's position, that it was appropriate to analyze the sale's price for contact lenses independently from the royalty fee paid for the license of the intangibles. ${ }^{252}$

The court first tackled the arm's length price for the contact lenses (paid by the taxpayer). It used the comparable uncontrolled price method and found that $\$ 7.50$ was not higher than the standard price charged for contact lenses in the industry (and therefore it does not reflect by itself a shift of profits away from the U.S. parent). The court noted that the fact that $\mathrm{B} \& \mathrm{~L}$ Ireland was a low cost producer did not matter, since the market price would be equal to that of the least efficient producer of the product. The government argued that the taxpayer would never go into the market and pay $\$ 7.50$ for a good that the taxpayer could manufacture itself for $\$ 1.50$; therefore, even if

${ }^{250}$ Bausch \& Lomb Inc. v. Commissioner, 92 T.C. 525 (1989).

251 The court determined that the taxpayer was under no legal obligation to purchase B\&L Ireland products and that B\&L Ireland had a mere expectation that its parent would purchase its products in the event worldwide demand was not as anticipated.

${ }^{252}$ Once the court decided that B\&L Ireland was not a contract manufacturer, these two payments do not tie to each other so that only a net payment is effectively required to be determined. Both the volume and the price of sales to the parent were subject to variations, which required separate determinations of the appropriate royalty payments made to the parent and the sales price paid by the parent. 
$\$ 7.50$ was the market price for other buyers it could not be the arm's length price for sale to the taxpayer. The court rejected this argument, finding that the fact that the taxpayer could have produced the lenses itself at the lower cost amount was also of no consequence, and that the power to determine who in a controlled group would earn income did not justify the application of section 482 .

With respect to the arm's length price for the license of the intangibles (by the taxpayer), the taxpayer argued that 5\% was an appropriate royalty fee, but proposed that it be based on the average realized price earned by the taxpayer on its resale of contact lenses produced by $\mathrm{B} \& \mathrm{~L}$ Ireland. This was a concession made by the taxpayer at trial. The taxpayer argued that $5 \%$ was the standard royalty fee in the industry for the license of contact lens technology, and referred the court to two contact lens license agreements for the use of manufacturing technology. In addition, it conducted a rate of return analysis that found a return of $106 \%$ for B\&L Ireland and $66 \%$ for taxpayer, and asserted that this was consistent with the relative risks borne by each party. The court found that the intangible property in taxpayer's license agreement was superior to the licensed intangible in the proposed comparable agreement because the comparable agreement licensed new technology, which had not been shown to be commercially feasible. In contrast, the taxpayer's license agreement covered technology that had been proved to be successful for ten years. In addition, one of the taxpayer's proposed comparable agreements licensed new technology, which at the time of the agreement, was not approved by the FDA to produce contact lenses. This stood in contrast to the taxpayer's technology that was proven and had FDA approval. Also, there was a difference in experience between $\mathrm{B} \& \mathrm{~L}$ Ireland and the licensees in the comparable transactions. They were experienced manufacturers whereas B\&L Ireland was a new company that would not risk purchasing new and unproven technologies that the more experienced companies may contemplate acquiring. Based on these and other supporting considerations the court rejected the taxpayer's comparables. The government's argument was based on an appropriate mark up of B\&L Ireland costs $(\$ 1.50)$ and a permitted return of $50 \%$ to $100 \%$ to manufacture the lenses, with the remainder of the $\$ 7.50$ sale price allocated to a royalty fee.

The court then engaged in an independent valuation study. ${ }^{253}$ The

${ }^{253}$ Id. (citing Treas. Reg. $\$ 1.482-2(\mathrm{~d})(2)($ iii) (2006) as authority that it may consider prospective profits to be realized by the licensee in determining the arm's 
court began by reviewing the projected earnings that the taxpayer had prepared in connection with creation of B\&L Ireland, which were tenyear cash-flow projections from the proposed investment. The court adjusted the cash-flow projections including a reduction of earnings in years five through ten to account for the court's anticipation of the introduction of new extended wear contact lenses and the resulting slow down in demand for daily contact lenses. In addition, the court factored in a reduction in price in the later years to account for new low cost competitors entering into the market. Based on the profits from these projections the court undertook to divide the profits between the taxpayer and B\&L Ireland. The court noted that based on its revised profit projections that the royalty rate suggested by the government would lead to B\&L Ireland operating at a loss, while the rate proposed by the taxpayer would result in an internal rate of return in excess of $35 \%$, which the court felt was inappropriate. The court then referred to the $25 / 75$ rule of thumb profit split between licensors and licensees; however, it was determined that this was too generous given the fact that B\&L Ireland had nothing unique to contribute while the taxpayer was contributing its marketing and sales network as well as the production technology. ${ }^{254}$ The court concluded that a 50/50 split was appropriate, which translated into a royalty fee of $20 \%$.

By now, the reader should be familiar with the pattern: independent study by the court, based on "fair" approximations and rules of thumb, rejecting the parties' information (with no deference to the government) and ignoring the arm's length standard. ${ }^{255}$

length price).

${ }^{254}$ The court comments that the $25 / 75$ split is appropriate in a normal license situation when each party posses something unique (i.e., technology/patents/etc) and in order to make a product both parties need to come together and share their respective technologies.

${ }^{255}$ In another case that I chose not to elaborate on due to space considerations, the tax court followed a similar thought process. It rejected the transfer prices suggested by both the taxpayer and the government, engaged in an independent all facts and circumstances analysis based on the large number of comparable transactions presented to the court, and made the unsurprising judgment call and rules for a royalty rate that is the exact average between the lowest and the highest royalty rates charged in the comparable transactions presented to the court. Podd $v$. Commissioner, 75 T.C.M. (CCH) 2575 (1998) (dealing in part with an appropriate royalty rate to be paid for the exclusive right to manufacture, market, and sell a "hideliner" (intermodal container liner system) subject to a patent held by the developer who licensed it to a company he owned). This case is a particularly good example for the helplessness of the court when faced with a large number of inexact comparables and contradictory expert testimonies. 


\section{Sundstrand $d^{256}$}

The taxpayer expanded the operations of its wholly owned Singapore subsidiary (SunPac) by licensing to it certain industrial property rights. The license permitted the manufacture of CSD spare parts, ${ }^{257}$ and the use of trademarks associated with the CSD, along with the taxpayer's agreement to provide technical assistance. The set royalty was $2 \%$ of the net selling price of each part manufactured. The vast majority of parts manufactured were sold to the taxpayer at a discount of $15 \%$ off SunPac's catalog prices. The Service assessed the tax on the taxpayer based on SunPac's being a subcontractor, ${ }^{258}$ and computed SunPac's income on a cost-plus basis, limiting it to a mark up of $38 \%$. Relying on Bausch \& Lomb, the court found that SunPac was not a subcontractor and that the Service's assessment was accordingly arbitrary and capricious.

The court found that SunPac sales and prices were not guaranteed by the taxpayer and consequently that SunPac bore market risk with respect to its operations. In addition, the court found that the selling price for the spare parts and the royalty rate for the intangibles had to be addressed independently. The court found that a discount of $20 \%$ of catalog prices is appropriate, and based its decision on agreements that the taxpayer had with third parties. With respect to the royalty rate, the taxpayer argued that a number of transactions, wherein it licensed CSD manufacturing technology to independent third parties, were comparable to the SunPac license agreement. The government argued that significant distinctions existed between the agreements. ${ }^{259}$

${ }^{256}$ Sundstrand Corp. v. Commissioner, 96 T.C. 226 (1991); see also Seagate Technology, Inc. v. Commissioner, 102 T.C. 149 (1994). I chose not to elaborate on this case due to space considerations.

${ }^{257} \mathrm{CSD}$ is a constant speed drive used to drive an airplane's engine generator at a constant speed.

${ }^{258}$ This is an argument similar to the contract manufacturing argument in the prior cases described before. See supra note 256.

259 These differences included: (1) that the SunPac license was limited to licenses for CSD unit for commercial aircrafts, where the comparable transaction included licenses for CSD units for military aircrafts and guided missiles; (2) that the SunPac license limited SunPac's right to manufacture spare parts only, the comparable transactions included licenses for a much broader range of products including engineering design, manufacture, assembly testing, inspection, and servicing of CSD units; (3) that the SunPac agreement provided that the costs of technical assistance were to be recovered as part of the royalty and the comparable transaction required the licensee to bear the cost of technical assistance; (4) that the comparable transactions additionally required the licensee to pay a substantial lump-sum 
The court focused on two differences between the SunPac license and the comparables, the first being differences in rights regarding manufacturing intangibles and the second regarding differences in marketing intangibles.

In the comparable transactions, the sunset provisions permitted the continued use of unpatented manufacturing technology and data that had been provided to the licensee during the term of the license, for a royalty of $2 \%$ to be paid over 15 years. In contrast, the SunPac royalty payments were scheduled to end in 8 years and thereafter SunPac was granted access to any future improvements to CSD manufacturing technology that may be made by the taxpayer. Regarding the marketing intangibles, the court emphasized the fact that the license permitted SunPac to sell CSD spare parts into markets wherein the taxpayer had previously sold CSDs. Thus SunPac was in essence given a captive market within which to sell its spare parts, as once one of taxpayer's CSDs were included within an aircraft it was prohibitively expensive to replace that unit with a different model. In contrast, the comparable transactions were limited to selling CSD spare parts only to the licensee's own customer, which the licensee would have had to develop through its own marketing activities.

The court also reviewed another comparable, identified as the Concorde license agreement. The court found two key distinctions between this license and the SunPac license. First, the court distinguished that the Concorde CSD involved new and untried technology and that this led to the licensee taking on significantly more risk in the Concorde license. The distinction was that CSD, as a non European company was effectively prohibited from competing directly for sales of CSDs in this market.

The taxpayer then argued that there was a $6.5 \%$ royalty rate standard applicable to the license of CSD technology within the industry as a whole. The court found that the SunPac license was unique in that it included invaluable marketing intangibles not found in other agreements. The court then stated that the $6.5 \%$ could be utilized as a base rate upon which adjustments could be made, particularly adjustments to reflect SunPac's limited risk and the valuable marketing intangible it obtained via the license (these marketing intangibles related to the captive market SunPac had for spare part sales). The court then referred back to third party license

payment; (5) that the SunPac license was worldwide and the comparables were limited in geographical scope; and (6) the SunPac royalty was to cease after eight years while the comparables provided for continuing sunset royalty payments. 
agreements wherein the taxpayer licensed CSD technology to third parties and found that portions of some of these agreements related to sales of CSD spare parts that were permitted to be made outside of the licensee's allocated territory. Such parts sales were permitted when the aircraft, to which the licensee had made the initial CSD sale, had been relocated to a different jurisdiction. In this case, a $10 \%$ royalty fee was imposed on such sale. The court adopted this rate as an appropriate transfer price.

Finally, the court found that all of the taxpayer's other comparable licenses contained a separate charge for providing technological support services. But taxpayer provided that SunPac's charge for technical assistance was to be paid out of the $2 \%$ royalty fee. The court held that the SunPac provision allowing for the payment of such fees out of the royalty payment was not at arm's length because the taxpayer would not offer this payment provision to an unrelated party. Based on this, ${ }^{260}$ the court found that the provision of such services was not integral to the taxpayer's business and allocated income to the taxpayer based on its costs of providing these services.

The case is an important example of the discomfort of the court with the arm's length standard and the use of comparable transactions to establish transfer prices. It is an interesting case since it involves comparable transactions in the same/similar product. Note that the single factor the court adopts here from the parties' positions is the industry standard of $6.5 \%$ presented by the taxpayer to be used as a baseline for the court's independent recalculation of the proper transfer price.

\section{Westreco ${ }^{261}$}

The issue at hand was the proper fee for research and development ("R\&D") services. Westreco performed R\&D services (food related research) for Nestle, its parent company (headquartered in Switzerland) for which it was paid a fee. The fee was based on Westreco's costs and a markup of between $3.5 \%$ and $7 \%$ of those costs. The government countered with a "salary multiplier" method to determine an appropriate fee to be paid to Westreco. It used a multiplier of three on all of the taxpayer's salary costs including indirect costs such as vacation, medical etc.

\footnotetext{
${ }^{260}$ See also Treas. Reg. \$1.482-2(b)(3) (2006).

${ }^{261}$ Westreco v. Commissioner, 64 T.C.M. (CCH) 849 (1992).
} 
There were certain procedural issues involved, ${ }^{262}$ but for our purposes, the important ruling is that the court found that the Service made a fundamental error in basing the salary multiplier on all of the taxpayer's employee costs rather than limiting it to direct salary payments. ${ }^{263}$ The court held that the salary multiplier method applied by the Service was not an accurate method to use in determining the correct revenue for a unique firm like the taxpayers. Taxpayer then introduced evidence to show that taxpayer's pricing practices were similar to four comparable corporations.

The taxpayer's expert submitted these four comparables and utilized three criteria upon which they were compared with the taxpayer. The first was business relations with clients, where the principle issue was the extent to which the companies retain an interest in the product of their research or are merely conducting research for a client whom retains all rights to the research performed. The second was financial comparability, where a comparison of fixed investment costs was made and the third factor was the degree of business risk undertaken by the companies. Overall, the key factor was the low business risk undertaken by Westreco, as all of its expenses were covered under their cost-plus formula of payment, and the fact that Westreco did not have to regularly solicit clients to ensure continuity of work. A number of profit ratios of the corporations were then compared, and the taxpayer argued that a lower profit level was appropriate for the taxpayer due to its limited risk. The government attempted to come with a list of different (comparable) companies (15 companies) whose identity was derived from their sharing the same SIC code as the taxpayer. The court rejected the Service's comparables, noting the diverse fields within which these firms operated, including: nuclear power plant construction and operation, map making and breeding of research

${ }^{262}$ Looking behind the statutory notice of deficiency. Petitioner was able to obtain the testimony of the CIR employee responsible for the assessment. The court found that the Petitioner's high burden (the arbitrary and capricious standard) entitled it to examine the Respondent and the method it used to exercise it's discretion, and that this did not constitute looking behind the statutory notice of deficiency.

${ }^{263}$ Additionally, the salary multiplier method is a compensation method used in large engineering and construction firms for services that are general in nature (i.e., not limited to a specific project), and not in small R\&D firms. The salary base used was wrong also because the expert did not allocate salaries out of the salary base for services performed to a different company that were not at issue in this case at all, and the expert based the taxpayer's income adjustments on billing methods of two corporations which are not comparable to the taxpayer. 
primates and canines, and concluded that they were not comparable. Thus, the court accepted the taxpayer's methodology and found that the fee was at arm's length.

This is an interesting case that technically focuses on services, yet these are $R \& D$ services based on which values of resulting intangibles are established. The case clarifies the reluctance of the courts to dive into the comparability world. Once the court is provided with reasons not to accept direct asset comparability, it immediately switches its focus to more remote methodologies and reliance on accepted commercial norms. Consequently, the court's analysis gets further away from simple arm's length standard application that is supposedly the ideal of our current regime. The court also, consistently, ignores the burden of proof rules.

\section{Perkin-Elmer ${ }^{264}$}

The taxpayer was a U.S. corporation that established a Puerto Rico subsidiary (PECC) and licensed to it the right to manufacture and sell spectrophotometers and accessories, gas chromatography accessories and HC lamps (generally scientific measurement instruments) and the provision of all design and manufacturing information related to these products. The royalty was $3 \%$ of sales. PECC purchased parts (described as parts kits) from the taxpayer. The kits were intended to be assembled into a designated finished product. PECC manufactured the products and sold them back to the taxpayer, who then resold them in various markets. ${ }^{265}$

The court addressed the issue of the arm's length price of finished products independently of the royalty issue. Court used the resale price method with reference to comparable sales to determine the arm's length price on the sales of each finished product. Once again, the court rejects to use taxpayer's or the Service's proposed comparable sales on the basis that they are not comparable and then the court independently values an arms length resale margin. With respect to the parts PECC purchased from taxpayer, the taxpayer argued for the comparable uncontrolled price method, an argument the court ultimately adopted, as there were a number of other

${ }^{264}$ Perkin-Elmer v. Commissioner, 66 T.C.M. (CCH) 634 (1993).

${ }^{265}$ The Service characterized PECC as a consignment contract manufacturer and assessed its taxes on a cost plus basis. At trial the government abandoned this position and relied on alternative legal arguments. The court found that this abandonment of both the factual and legal basis of the notice of assessment caused the determination to be arbitrary and capricious. 
manufacturers selling identical parts. ${ }^{266}$ The government argued that the parts kits sold to PECC embodied various manufacturing intangibles of the taxpayer, and that the sale price of these kits should be adjusted accordingly. In theory the court agreed that the kits did embody manufacturing intangibles, but felt that these could be more simply dealt with under the royalty fee determination. The government's experts used the cost plus method and utilized a means of computation that the court described as novel and complex, the court summarized one of the two variations of these computations as follows. First the gross margin earned by the taxpayer on the sale of such products was computed (this was based on a period before the manufacturing license agreement with PECC was entered into and as such involved the Taxpayer in both the manufacturing and distribution process), this amounted to a $52 \%$ gross margin, then the manufacturing margin was isolated by subtracting a $37 \%$ distribution margin which was obtained from the analysis of a comparable third party transaction involving the distribution of a comparable product. Then the 19\% manufacturing margin (based on sales) was converted to $40 \%$ margin over costs. Lastly this $40 \%$ margin was applied to taxpayer's costs of manufacturing the parts kits. The expert backed into the appropriate percentage markup on parts rather than deriving the markup percentage directly from a comparable transaction. The court had a problem with this because this type of indirect approach is very sensitive and leaves little room for error.

The parties and court agreed that the comparable uncontrolled transaction method should be used with respect to the royalty, although each party proposed several adjustments to the arm's length price of the comparable transaction. The adjustments made by the court to the comparable transaction were as follows: (1) The definition of "customers" in the comparable Hitachi licensing agreement was in issue with the government's arguing that the Hitachi royalty computation was based on prices for sales to consumers (end users), while the PECC royalty computation was based on sales to intermediaries. The court found that insufficient information was available to determine whether Hitachi planned to sell to end users exclusively and declined to make an adjustment. (2) The court considered a downward adjustment due to the limited use PECC

266 The Court does use the comparable uncontrolled price method but rejects taxpayer's calculations as ignoring certain circumstances that create differences between controlled and uncontrolled transactions. Therefore the court independently values the arm's length price and determines that based on the entire record that the amount PECC paid to taxpayer for parts were arm's length. 
made of the technical manufacturing documentation as compared to Hitachi's use of this information, due to the use by PECC of the parts kits. The court noted that the contractual right to such documentation was a part of the license agreement and did not make an adjustment. (3) The government argued that an upward adjustment to the Hitachi license was required to compensate for the limited geographical area in which Hitachi could sell it's manufactured products (Japan and several other countries), and the worldwide license rights conveyed in the PECC agreement. The court made no adjustment, noting that although Hitachi's rights were limited, there was no evidence that this led to a lower royalty fee, or that the taxpayer's inability to penetrate the Japanese market was responsible for a lower royalty fee. (4) The taxpayer argued that a downward adjustment was appropriate as the Hitachi license included the right to manufacture a broader range of Taxpayer's products than PECC's license agreement. Although Hitachi did not actually make use of this broader provision, the taxpayer argued that Hitachi's option to do so had value and warranted a downward adjustment to the Hitachi royalty fee. The court found that the value of such an option was too speculative in nature and did not make an adjustment.

Note again how the court accepts comparables offered by the parties without the adjustments that the parties themselves made. For example, the parties acknowledge that the comparables are not exact, yet the court uses them as if they were exact comparables. The court again is not capable of sophisticated analysis of inexact comparability. The court essentially engages in an independent transfer pricing study, regardless of burden of proof issues and the mode of analysis required by the regulations.

\section{8. $D H L^{267}$}

The trademark "DHL" was conveyed from DHL to DHLI (DHL International) in connection with the purchase by a group of investors of a $57 \%$ interest in DHLI. In addition, the court reviewed DHLI's use of the trademark (without paying compensation to DHL) for a number of years prior to that. In this case, both the taxpayer and the government used a relief from royalty income approach (i.e., cash method) to value the trademark, and came up with very different results. Taxpayer estimates were 50 million, while the Service's estimates were in the neighborhood of 300 million. The difference

${ }^{267}$ DHL Corp. v. Commissioner, 76 T.C.M. (CCH) 1122 (1998), rev'd in part, aff'd in part and rem'd, 285 F.3d 1210 (9th Cir. 2002). 
stemmed from their disagreement over the existence and income attributable to other intangibles owned by DHLI. The Service says that the trademark (the DHL name) was the primary intangible asset and therefore the majority of the value of all intangibles. Where the taxpayer says that DHL's other intangibles (DHL network, ability to efficiently deliver/reliable performance, cost advantages such as the DHL infrastructure) was the most valuable intangible asset and worth substantially more than the DHL trademark.

In addition, both parties made reference to the purchase price paid by the foreign investors ( 500 Million) for the $57 \%$ interest, and reduced this by amounts allocated to the tangible assets of DHLI, coming up with a value of approximately 250 to 300 million for the companies off balance sheet assets. Each used this amount to support their relief from royalty calculations. The taxpayer argued that the sale of the trademark was at arm's length due to the presence of the investors in the negotiations and the fact that the transfer was an integral part of the investors buy in. The court found that the Investors were indifferent as to the allocation of the purchase amount between shares and the trademark and that the value put on the trademark (20 Million) was tax motivated. Thus, the court found that this was not an uncontrolled transaction.

The court took a rough and ready approach to the valuation which it seems to have done in the majority of these cases - and started with its calculation of the value of all DHLI intangible assets (essentially the grossed up value of the investors purchase price less the book value of DHLI assets). The court then indicated its belief that DHLI had a number of other intangible assets (e.g., know-how and systems in place) that enabled it to effect distributions internationally in an efficient and cost effective manner, and that DHLI's growing profits were equally attributable to the trademark and these other intangible assets. This gave the trademark a value of 150 million dollars, which the court discounted to 100 million based on the fact that an independent third party would not pay full value for an asset whose ownership was subject to legal challenge. ${ }^{268}$

The court continued to value a royalty fee for prior

${ }^{268}$ The ownership of DHL in the international Trademark rights was not clear. It was adduced at trial that the license agreement between DHL and DHLI may not have given DHL a sufficient degree of control over the operations of DHLI, and that this could raise the possibility that DHL had abandoned the international portion of its trademark. In addition, DHLI made numerous trademark filings in foreign countries under its own name and this under foreign law could lead to the conclusion that DHLI was the owner of the DHL trademark in those countries. 
uncompensated use of the trademark by DHLI. In this context, the taxpayer made three arguments. First, that no royalty was due from DHLI for the use of the DHL trademark because DHLI was a developer of the trademark. Alternatively, DHL argued that if the court found that DHL is the owner/developer of the trademark, then no cash royalty would be due because the mutual agency agreement granted both DHL and DHLI reciprocal rights. ${ }^{269}$ Finally, the taxpayer argued that DHLI's agreements with independent contractors in foreign locations permitted their use of the trademark but provided for no fee with respect to the trademark use. The court rejected all three of taxpayer's arguments. First, the court determined that DHLI was the developer of the trademark (see below). Second, the court held that taxpayer did not meet its burden of showing that the reciprocal benefits were within the range of arm's length. Lastly, the court held that the royalty-free use of the trademark by independent parties was not shown to be a sufficiently similar transaction to set an arm's length charge.

The government adduced evidence of royalty payments for the trademark's use in a variety of circumstances, payments ranging from 0.7 to $15 \%$, and argued for a royalty of $1 \%$. For reasons the court did not review, the government's experts felt that a royalty at the lower end of the range was appropriate. The court accepted the .75 rate and noted that this equaled the rate which DHL had agreed to pay DHLI for use of the trademark after the transfer of the trademark to DHLI.

With respect to the application of the developer/assistant rules, the court concluded that due to the absence of a cost sharing agreement with respect to the intangible and due to the existence of a valid licensing agreement between DHL and DHLI, that DHLI could not be a developer of the intangible. The taxpayer argued that in the alternative DHLI was an assister under the regulations, and that any allocation of income to it should be offset by amounts spent by DHLI in assisting in the intangibles development. The court denied any offset under the rationale that DHLI did not establish that its expenditures connected with the trademark (principally a significant amount of advertising expenditures) were in excess of expenditures that an independent licensee would expend in similar circumstances.

In appeals, the taxpayer argued that the court failed to sufficiently spell out its reasoning with respect to the valuation of the intangible.

${ }^{269}$ In other words, arm's length consideration includes more than just cash royalty payments for use of the intangible property and that the transfer or use of other reciprocal rights can also represent fair market value. 
The appeal court reviewed the tax court's valuation and noted that it had given a step by step account of its reasoning and that although the method of valuation had its deficiencies (i.e. the use of book value may not reflect the true value of a tangible asset), the taxpayer failed to demonstrate clear error. The appeals court did reverse the tax court on its interpretation of the developer/assistant regulations and found that they made an error of law in equating developer status with a legal ownership interest in the intangible. ${ }^{270}$ Based on the costs incurred and risks borne by DHLI in connection with the trademark, the appeals court found that DHLI was a developer of the international trademark rights under the Regulations, and it reversed the tax courts allocation of 50 million of income to DHL that arose from the transfer of the legal rights related to the international trademark to DHLI. In all other respects, the tax court opinion was upheld.

On remand, ${ }^{271}$ the tax court found that DHL had overpaid taxes in the amount of 28.7 million, this amount included interest and penalties.

\section{Endnotes on the Practice of Transfer Pricing for Intangibles}

It should be apparent to the reader by now that compliance with the transfer pricing rules for intangibles is extremely burdensome, more so even than other transfer pricing tasks. Twenty years ago, a government's policy ("white") paper acknowledged that half of the transfer pricing cases at the time involved intangibles. ${ }^{272}$ Now, despite the later revisions of the regulations, and the addition of the commensurate with income requirement to section 482 - the single statutory amendment that reflect the importance of this issue - the portion of transfer pricing disputes involving intangibles only increased since, and threatens to continue to do so. ${ }^{273}$ Transfer pricing

${ }^{270}$ The Court erred in imposing the requirement that assister status is dependent upon a showing that expenditures related to the intangible were in excess of those that a comparable licensee would expend. This is because the tax court applied the 1994 regulations, which provided for such a standard but the applicable regulations that the tax court should have applied were the 1968 regulations which did not impose such a burden. The court of appeals does go on to say in dicta that even if the 1994 regulations were in effect, the tax court would still be incorrect.

271 Tax Court on Remand, 11 Transfer Pricing Report 387, 09/04/2002.

272 See I.R.S. Notice 88-123, 1988-2 C.B. 458, 466 n.52.

273 Together with cross-border provision of services that often go hand-in-hand with the transfer of intangibles, this is clearly the most important and disputable aspect of transfer pricing today. See, e.g., ERNST \& YOUNG, 2007-2008 GLOBAL 
in general became the single most important issue faced by MNEs, according to a recent study. ${ }^{274}$

Yet, despite the importance of the issue, this article demonstrates the very superficial attention taken by the regulations to intangibles and the reasons for the difficulties of applying these rules to transfer of intangibles. The review of the court cases above is a striking exhibition of the uselessness of the rules and prescribed methods themselves. Case after case, the courts simply resort to independent, freestyle application of what they understand to be the arm's length principle, regardless of traditional court procedures, and, more importantly, regardless of the regulations. The courts do feel bound by the arm's length principle, so even when they are frustrated with the impossibility of its application in the mode required by the regulations, they resort to their own interpretation of the standard (not the regulations). Awkwardly, this approach can lead courts to reject at times alternative valuation methodologies that the regulations permit in the context of the fourth method, even if such methodologies are conventional in the practice of valuation. ${ }^{275}$ This approach of the courts further limited the chance of the system "getting it right," confining the analysis to the arm's length standard rhetoric, notwithstanding its effectiveness, reliability or desirability. The fault should not be laid at the steps of the courts, since they, similarly to taxpayers in general, were provided with unworkable rules. ${ }^{276} \mathrm{Next}$, the conclusion of the article makes the argument that part of the fault is in the choice of the arm's length standard, and

TRANSFER PRICING SURVEY, supra note 8, at 14.

${ }^{274}$ Id. at 2.

${ }^{275}$ For a classic example of this unfortunate development, see Nestle Holdings $v$. Commissioner, 152 F.3d 83, 88 (2d Cir. 1998), in which the Second Circuit refused to accept a valuation of a trademark based on the relief-from-royalty - a primary income based method - , arguing that it does not adequately reflect the value of the transferred intangible. See also supra Part III. It is easy to read between the lines that the court meant to say that this method is not based on the arm's length principle and therefore it felt uncomfortable with using it. Also interesting is the simple conclusion of the court that the various valuation methodologies result in different valuations, and therefore some of them may not be used - meaning to say that valuation that does not reach the number that an arm's length based analysis would reach is unacceptable. This opinion is even more amazing once we remember that it reversed a holding by the professional tax court that accepted the use of the relief-from-royalty method.

${ }^{276}$ See, e.g., Michael C. Durst \& Robert E. Culbertson, Clearing Away the Sand: Retrospective Methods and Prospective Documentation in Transfer Pricing Today, 57 TAX L. REV. 37, 40 (2003). 
another part is in its rigid and rhetoric application.

\section{CONCLUSION: THE FUTURE OF TRANSFER PRICING}

This article analyzes our current transfer pricing regime as it applies to transfers of intangible assets. This concluding section evaluates the desirability of this regime in light of the analysis. It begins with an extraction of the achievement of the current regime, and a sober realization of its actual effects on our society. The conclusions are then generalized to an assessment of the arm's length principle. The transfer pricing analysis of transfers of intangibles is probably the most significant challenge that or current arm's length based regime faces, and therefore it is particularly important to evaluate its effectiveness in this context. Finally, the current regime is contrasted against a formula based transfer pricing regime in order to highlight the benefits of such alternative regime in comparison to our arm's length based regime with respect to the challenges that intangibles pose to transfer pricing in general. We begin, however, with what we learned about our current law in this article.

\section{A. The Reality of Current Law}

We learned in this article that despite the evolution in transfer pricing rules, and the inclusion of special rules that apply specifically to transfers of intangibles, such rules do not account for the unique features of intangibles that make them a difficult challenge to any transfer pricing regime.

The regulations provide four permissible methods, among which one - CUT - the most direct application of the arm's length method is practically irrelevant, and another is a basket residual - unspecified method. This leaves the taxpayer with two methods - CPM and profit split - in terms of specific guidance. Nonetheless, even these methods provide little specific guidance. They include almost no particular reference to intangibles, and no reference at all to the unique features of intangibles that make them difficult to price. Even in terms of appearance, both of these methods were not rewritten into the regulation that deals with transfers of intangibles ${ }^{277}$ and continue to apply to all cross-border transfers almost similarly. ${ }^{278} \mathrm{CPM}$ and profit split present also substantive difficulties. They are both essentially

277 Treas. Reg. § 1.482-4 (2006).

${ }^{278}$ See Treas. Reg. $\S 1.482-5$ (2003) (covering CPM); Treas. Reg. § 1.482-6 (2006) (covering profit split). 
statistical methods that represent approximations rather then direct valuation or pricing. They rely on normal, average market results and not on particular transactions or assets. This, of course, represents a deviation from the arm's length principle and its alleged objectivity promise. It also ignores the particular uniqueness of intangibles and transactions in intangibles that are typically less conforming to market, industry, or sectoral norms. CPM and profits split, by design, are not built for accuracy and capture of values generated by abovenormal profits. Both of these methods are based on the market approach to valuation, ${ }^{279}$ yet, they both produce market ratios, approximations, standards and norms - not market prices.

Related parties need additional mechanisms to come up with their transfer prices, since eventually they are required to report a single dollar amount (number) on their tax returns. No matter what nominal method they use, specified or unspecified, taxpayers (and the courts, as we have seen) are bound to make several judgment calls in the process of coming up with the desirable number, some of which are based on valuations of the intangibles involved in the reported transactions. The claim of this article is that at each decision level the law permits almost frictionless flexibility to taxpayers. This flexibility is the combined and results in significant deviations from the desired accurate result that our transfer pricing rules purport to target. Such inaccuracy accumulates and creates a significant advantage to taxpayers subject to transfer pricing analysis (MNEs), particularly if they rely heavily on intangibles, in comparison to other taxpayers. ${ }^{280}$

\section{B. The Challenges Faced by the Arm's Length Principle}

The most fundamental consequence of the current regime is that MNEs are particularly advantaged in comparison to other enterprises, and their advantage is more significant the more heavily they rely on intangibles to generate profits. ${ }^{281}$ Such taxpayers, but also (essentially) all other business taxpayers, are advantaged vis-à-vis the Service in this game. This is particularly true due to the rigidity of the regulations and their conservative evolution. The Service must follow the general path prescribed by the regulations, yet such path is not only limiting, but also limited, which leads to multiple eventualities

279 These methods are often mixed with other approaches.

280 The advantage is above and beyond the costs of transfer pricing compliance. See also sources cited supra note 121.

281 See also David R. Hardy, Assignment of Corporate Opportunities - the Migration of American Intangibles, 730 PLI/Tax 645 (2006). 
when taxpayers are required to use unprescribed valuation methodologies, including new, more sophisticated models that thrive in today's market consequently.

The use of modern, more sophisticated valuation methodologies could be desirable, yet the use of such methodologies is arbitrary from the perspective of the system. In some cases taxpayers may use it, such as when the prescribed methods do not produce a satisfactory result, or when such methods call for secondary valuations that do not follow prescribed methods (such as valuations of contributions of certain intangibles to the process of development of the tested intangible). In other cases, however, the taxpayer may not (not because the prescribed methods produce better results, but because they produce satisfactory enough results for them). The Service, of course, is even in a more inferior position. Among the difficulties of using modern methodologies are: (1) that they constantly develop; (2) they often rely on a mix of valuation approaches, so the rhetoric of adherence to the arm's length standard may prove to be more difficult to keep if they were allowed; (3) they are numerous, so it would be more difficult to administer and enforce from the government's perspective - especially the best method rule would be impracticable - and also since it is very difficult to include in the rigid regulatory system that we have at the present; (4) many of the new methodologies are proprietary and rely on proprietary databases that if allowed may raise questions of fairness, equality etc. The main issue, however, is that the prescribed methods are so weak that taxpayers are in practice using some of the proprietary tools quite frequently, yet with no regulatory ordered supervision.

Novel valuation methodologies and proprietary databases are not the primary challenge that the arm's length standard faces. It is the false adherence to this standard that does it, and ties the hands of the Service in fighting this difficult battle. The transfer pricing methods preferred by the Service, CPM and profit split, are both basically statistical methods based on approximations and almost "thumb rules." The manner in which the courts dealt with the relevant tax cases demonstrates this most clearly. The system sends signals of helplessness, attempting to fulfill its tasks to the best of their ability without the support of coherent, practical set of rules. The fact that no clear hierarchy between the methods is imposed, is the first indicator to this lack of confidence in the arm's length standard. This uncertainty was covered up by the "best method" requirement, yet no realistic guidance was given, which left the choice, and therefore, also the advantage, to the taxpayers. The system is designed so that 
taxpayers who take transfer pricing seriously have the advantage of setting the rules of the game and the facts presented in the way they want them to be presented. Now, surely MNEs will respond that this is not correct and that they would be very happy to get rid of the rules and the expenses involved, yet, this is not an option. The question is only which of the alternatives regimes is superior. Moreover, in the attempt to hold on to the arm's length "ideal," the arm's length range concept was introduced into the rules. Again, this is a reasonable rule if one accepts arm's length as the only possible principle guiding the regime, since all agree that an accurate comparable price is impossible to establish. But, it also proves the same thing: that this system cannot deliver the promise of arm's length, and does not take advantage of the potential advantages of the market approach to valuation. The averaging solution of the arm's length range rule creates an embedded inaccuracy and an advantage to taxpayers in this context. The comparability requirement and guidance have a similar effect, because the current regime does not account for levels of comparability or "accuracy." Comparability analysis can result either in acceptance of the suggested comparable or not, notwithstanding the degree of deviation and the degree of in accuracy of alternative methods. This is further explored in the next section.

In conclusion, the theoretical advantage of the arm's length standard, based on a classical market approach to valuation, is lost in practice. It remains merely rhetoric, replaced by workable piecemeal mechanisms, and whose main quality is that the government views them as noncontradictory of the arm's length rhetoric. Next, I add to this critique that the arm's length is not only unworkable, but also conceptually inferior to a formula based transfer pricing regime.

\section{The Future of Transfer Pricing Is in a Formula-Based Regime}

The inadequacy and inappropriateness of the arm's length standard have been extensively explored in the last few decades. ${ }^{282}$

${ }^{282}$ See, e.g., Louis M. Kauder, Intercompany Pricing and Section 482: A Proposal to Shift from Uncontrolled Comparables to Formulary Apportionment Now, 58 TAX NoTES 485 (Jan. 25, 1993); Stanley I. Langbein, The Unitary Method and the Myth of Arm'sArm's Length, 30 TAX Notes 625 (Feb. 17, 1986); Paul R. McDaniel, Formulary Taxation in the North American Free Trade Zone: A Policy Perspective, 49 TAX L. Rev 691 (1994); John Turro, The Battle Over Arm'sArm's Length and Formulary Apportionment, 65 TAX NOTES 1595 (Dec. 26, 1994); see Ackerman \& Chorvat, supra note 166 (promoting expansion of profit split and its formulary apportionment elements, together with modern financial models); Avi-Yonah, supra note 8; Hardy, supra note 281; Walter Hellerstein, International Income Allocation in the Twenty-first 
The contribution of this article to the literature is to support this criticism of the arm's length standard from the specific angle of the treatment of intangibles, and to promote an alternative, formula based transfer pricing regime. It argues not only that a formula based transfer pricing regime is practically more desirable, but also that it is theoretically superior to our current arm's length based regime.

First, however, the superiority of a formula based transfer pricing regime over the current regime should be demonstrated. The key difficulty that this arm's length based regime faces is the frequent reliance on comparability and valuation, which often results in high level of compounded inaccuracy. This inaccuracy is inevitable under an arm's length based regime, because by definition such a regime does not account for the fundamental difference between related and unrelated transactions and creates a (necessarily false) fiction that such transactions are interchangeable. The inescapable, heavy reliance on valuations that are, again, by definition estimations and approximations, contributes to the inaccuracy. Finally, our current system does not seriously account for the degree of incomparability between the tested transactions and the "comparables," 283 which adds to the inaccuracy further. One may argue that this is just a defect of the current system and could be amended. This is true, yet, a correction, if done coherently with the current system, would require an additional level of valuation and maybe comparables to asses the degree of incomparability. Such a correction may make the system more coherent, yet, it won't necessarily correct its inaccuracy since it relies on the same estimations, etc. I think that this picture is clear by now.

One may ask what is the problem with this inaccuracy. It is obvious that these are not market transactions, so standard and acceptable valuations methodologies, which are the best approximations, are made - this is the best that we can do with such transactions. My disagreement with this contention is threefold. First, our transfer pricing regime does not permit the use of all available valuation methodologies, and, in reality, it is only when the rules are not specific about the valuation itself that taxpayers are able to use

Century: The Case for Formulary Apportionment, 12 INT'L TRANSFER PRICING J. 103 (2005).

${ }^{283}$ It only tests a comparable for such degree of comparability. The result of this testing is essentially all or nothing. Either the comparability is sufficient, and then it is accepted as is, with no or little adjustment, or the comparability is insufficient and then the comparable cannot be used. No adjustments are allowed if the latter conclusion is made, notwithstanding whether other comparables are available or not. 
methodologies that may be more creative and sophisticated. Yet, even that would not revive the current regime because valuation and measurement are not designed to come up with a specific number. ${ }^{284} \mathrm{It}$ is rather normally designed to reduce uncertainty in order to improve business decisions that depend inter alia on the value of the tested assets or businesses. Conversely, in the context of transfer pricing, no market decisions are at stake but rather a one-dimensional regulation that attempts to come out with a single, accurate dollar amount, like all other dollar amounts that find their ways to our tax returns. However, this is impossible, an arm's length proponent will respond. It is not impossible, just misguided. There is no need to come up with transfer prices that look like market prices, and alternative regimes, such as formulary apportionment should be explored. This however, is my third point; the second is to explain what is bad about the inaccuracy of our transfer pricing regime.

The primary problem with the significant inaccuracy of the current regime is that it creates a huge advantage to MNEs in comparison to all other taxpayers. This advantage is not even equal for all MNEs but, as demonstrated in this article, grows in power the more heavily reliant on intangibles the MNEs are. These MNEs do pay a price in the form of compliance costs, yet these compliance costs are minimal in comparison to the advantage they get, so the playing field is not level, and at the same time such costs are simply wasteful as they do not represent any substantive goal - they just require investment of funds from taxpayers. In fact the current rules gave rise to the (wasteful) industry of transfer pricing compliance/valuation specialists. Note that the various levels of inaccuracy do not cancel each other on the average. This is because such inaccuracies are not just a result of margins of error, they are inherent in the process, and taxpayers control the product of the process. They are allowed, and have all the reason in the world, to be as close as possible to the boundaries of the range of acceptable results in each stage of the analysis. They will always chose the extreme that is the most beneficial to them, and each time they make such a choice, the level of inaccuracy works in their favor and compounds with prior and future levels of inaccuracies exploited in the process of establishing the transfer price. The system does not and will not compensate for these deviations because it does not recognize it. The bias in favor of MNEs may seem desirable to some, yet naturally achieving it in these means is extremely wasteful, imprecise and does not depend on any

284 See supra note 74. 
identified social benefit that the taxpayer delivers. Moreover, the benefit that the United States grants to its MNEs does not necessarily correspond to the regulation and tax systems of other countries. Double taxation or no taxation are still possible and are not dealt with by this regime.

This is a problem, since at the end of the day transfer pricing is simply part of our tax accounting regime, or the rules that measure the income at stake in the process of analysis and assessment of income tax due. It is an international tax rule in that its function is merely to divide income between two (or more) countries that may have a claim to that income. The income division function of our international tax rules rely on certain fundamental principles that are essentially universally accepted. One is the single tax principle, i.e., that income should be taxed once, but preferably not more than once, by some country (or a combination of countries). Another is the principle that the primary right to tax active or business income is vested to the source country - the country where the activity takes place, while the primary right to take passive activity is with the residence country (the residence of the investor). The single tax principle is important here because it is apparent that it would be very difficult to achieve in the world of the arm's length principle. Countries could cooperate and accept universal norms in theory, so that we could ignore the current (noncooperative) state of the international tax regime, and even the fact that multilateral approach to transfer pricing is basically nonexistent - transfer pricing establishment is largely a domestic unilateral process in practice. We cannot ignore, however, the nature of the application of the arm's length standard. Especially in the context of intangibles, it is expected that different countries will take different positions about comparability, reliability, adjustments, etc. Indeed, the details of the transfer pricing process and particularly valuations of intangibles vary significantly between countries. Even the permissible methods are not universal these days. We ignore, for simplicity, the effects of tax competition between countries in this context.

Global imbalance in this context is not inevitable. A formula based regime is based on the actual function of transfer pricing and not on a fiction of analogy to transactions that are completely irrelevant to this function. A formula-based regime simply divides income between the countries involved based on certain agreed principles and without the pretension of economic justification to the division principles. This division is naturally arbitrary at large because the division of income between two jurisdictions is arbitrary - it was 
earned once, by one firm, independent of the political division, whatever it is. This is exactly what our international tax regime does the division of income between countries is based on certain rough principles and particular compromises that are the fruits of negotiation, not economic principles. An important factor in such negotiations is the universal acceptance of some rough norms that countries accept because they believe these norms and more importantly a degree of convergence are beneficial to them in the end even if in the specific negotiations they may have achieved a better result without such universal norms.

It is very realistic to believe that countries will agree on a formula, based on which a new transfer pricing regime will be based, yet it is not realistic that countries will negotiate and agree on very detailed and fact specific protocols of valuations for intangibles. This article obviously argues that it is also unnecessary.

It is beyond the scope of this article to discuss the design of this formula based regime, yet one point is a natural consequence of the analysis above: the formula should focus on an accepted norm for division of income between countries that imitates the general norms we have. It should not be based on mechanisms that we think are appropriate just because we have experience with them if they do not fit the already existing international consensus. For example, there is no reason to imitate the formulae used by the U.S. states for their income tax systems that are usually based on assets, sales, and employees. ${ }^{285}$ The new emphasis, advocated by this article, is on the requirement that the formula-based transfer pricing reform conform to the basic premises of our general international tax regime, since it provides a distinct advantage to a formula-based transfer pricing regime over the current arm's length based rules. ${ }^{286}$ Otherwise, these

${ }^{285}$ Any reliance on assets, for instance, will invite the issue of valuations again in order to estimate the value of the intangible assets. Nonetheless, I think that is not a serious concern because in this case it is a single valuation that is not compounded with other estimations; it is itself the product rather than a tool to get to something else and it will be easier to coordinate acceptable means of valuation between the countries involved. Of course, if it proves to be problematic, it could be avoided by dropping assets (or even just certain intangibles) from the formula, which is impossible under our current regime.

${ }^{286}$ A formula-based reform also better captures the multilateral dimension of transfer pricing, which is currently ignored by our essentially unilateral arm's length based regime. Professor Reuven Avi-Yonah advocated a similar approach, although in a somewhat different context and reaching different conclusions. See Reuven S. Avi-Yonah, The Structure of International Taxation: A Proposal for Simplification, 74 TEX. L. REv. 1301 (1996). 
two regimes cannot be viewed so much as alternatives but as points on a continuum of solutions to the transfer pricing challenge. ${ }^{287}$ Formula Apportionment to Tax Income From Intangibles, 97 TNI 47-26 (Mar. 11, 1997). 